\title{
Microglia Implicated in Tauopathy in the Striatum of Neurodegenerative Disease Patients from Genotype to Phenotype
}

\author{
Huifangjie Li ${ }^{1}$, William C. Knight ${ }^{1}$, Pengfei Yang ${ }^{1}$, Yingqiu Guo ${ }^{1}{ }^{\circledR}$, Joel S. Perlmutter ${ }^{1,2,3,4,5}$, \\ John C. Morris ${ }^{2}$, Randall J. Bateman ${ }^{2}$, Tammie L. S. Benzinger ${ }^{1}$ and Jinbin Xu ${ }^{1}, *(1)$ \\ 1 Department of Radiology, Washington University School of Medicine, St. Louis, MO 63110, USA; \\ huifangjie.li@wustl.edu (H.L.); knight.w@wustl.edu (W.C.K.); pengfeiyang@wustl.edu (P.Y.); \\ Yingqiu.guo@duke.edu (Y.G.); perlmutterjoel@wustl.edu (J.S.P.); benzingert@wustl.edu (T.L.S.B.) \\ Department of Neurology, Washington University School of Medicine, St. Louis, MO 63110, USA; \\ jcmorris@wustl.edu (J.C.M.); batemanr@wustl.edu (R.J.B.) \\ 3 Department of Neuroscience, Washington University School of Medicine, St. Louis, MO 63110, USA \\ 4 Department of Physical Therapy, Washington University School of Medicine, St. Louis, MO 63110, USA \\ 5 Department of Occupational Therapy, Washington University School of Medicine, St. Louis, MO 63110, USA \\ * Correspondence: jinbinxu@wustl.edu; Tel.: +314-747-0693; Fax: +314-362-8555
}

Received: 7 August 2020; Accepted: 20 August 2020; Published: 22 August 2020

\begin{abstract}
We found interactions between dopamine and oxidative damage in the striatum involved in advanced neurodegeneration, which probably change the microglial phenotype. We observed possible microglia dystrophy in the striatum of neurodegenerative brains. To investigate the interactions between oxidative damage and microglial phenotype, we quantified myeloperoxidase (MPO), poly (ADP-Ribose) (PAR), and triggering receptors expressed on myeloid cell 2 (TREM2) using enzyme-linked immunosorbent assay (ELISA). To test the correlations of microglia dystrophy and tauopathy, we quantified translocator protein (TSPO) and tau fibrils using autoradiography. We chose the caudate and putamen of Lewy body diseases (LBDs) (Parkinson's disease, Parkinson's disease dementia, and Dementia with Lewy body), Alzheimer's disease (AD), and control brains and genotyped for TSPO, TREM2, and bridging integrator 1 (BIN1) genes using single nucleotide polymorphisms (SNP) assays. TREM2 gene variants were absent across all samples. However, associations between TSPO and BIN1 gene polymorphisms and TSPO, MPO, TREM2, and PAR level variations were found. PAR levels reduced significantly in the caudate of LBDs. TSPO density and tau fibrils decreased remarkably in the striatum of LBDs but increased in AD. Oxidative damage, induced by misfolded tau proteins and dopamine metabolism, causes microglia dystrophy or senescence during the late stage of LBDs. Consequently, microglia dysfunction conversely reduces tau propagation. The G allele of the BIN1 gene is a potential risk factor for tauopathy.
\end{abstract}

Keywords: microglia; tauopathy; striatum; oxidative damage; lewy body diseases

\section{Introduction}

The accumulation of misfolded proteins and various neuroinflammatory processes has been linked to the pathogenesis of several neurodegenerative diseases. In humans, the $M A P T$ (microtubule-associated protein tau) gene, located on chromosome 17, encodes tau protein, and is crucial for cytoskeletal stability and assembly. However, hyperphosphorylation of tau leads to the formation of neurofibrillary tangles (NFTs) [1,2]. A hallmark of Alzheimer's disease (AD) pathology is a multitude of senile plaques distributed throughout diverse brain areas, including the caudate nucleus, putamen, and ventral striatum. This hallmark has been observed in sporadic and familial 
cases of AD [3,4]. The relatively low frequency of striatal tauopathy observed in postmortem studies of Parkinson's disease (PD) brains is possible because tau accumulation is limited to the entorhinal cortex and medial temporal lobe, that is, tauopathy in PD brains may have a defined distribution pattern $[5,6]$. Recent studies indicate that microglia are associated with tau pathology spread in a mouse model overexpressing mutant human-tau, and are involved in tau pathology propagation through the brain $[7,8]$.

Microglia represents the chief immune defense of the central nervous system (CNS), and alterations in the microglial phenotype contribute to brain diseases $[9,10]$. In the 1-Methyl-4phenyl-1,2,3,6-tetrahydropyridine (MPTP) mouse model of PD, MPTP exposure leads to neurotoxic insults that result in the activation of extracellular signal-regulated kinase (ERK) in the microglia exclusively and not in the astrocytes of the striatum or substantia nigra pars compacta (SNc) [11]. Chronic activation of microglia promotes neuron death and neurodegeneration through the increased secretion of inflammatory molecules and cytokines [12]. Coincidently, our previous research with a different patient cohort shows that a significant reduction in $18-\mathrm{kDa}$ translocator protein (TSPO) density-a marker of brain microglia activation-is observed in the SNc of AD cases and dementia with Lewy bodies (DLB) cases compared with age-matched controls [13]. TSPO locates on outer mitochondrial membranes in microglia [14]. Thus, possible microglia dystrophy or loss in the late-stage of these neurodegenerative diseases could be implicated. Further, dystrophic microglia from the striatum of AD and PD brains were visualized in our immunohistochemistry study that displayed spheroidal swellings and fragmentation processes [15]. Microglia rapidly respond to pathological changes, switching into activated states, and introducing reactive oxygen species (ROS) [16]. It has been suggested that highly reactive radicals may cause damage to microglia [17,18].

We found that significant interactions between dopamine and oxidative damage in the striatum are involved in the late-stage of neurodegenerative diseases [19]. ROS's toxicity is reinforced by the presence of myeloperoxidase (MPO). This enzyme catalyzes the reaction between hydrogen peroxide and a chloride ion yielding hypochlorous acid ( $\mathrm{HOCl}$ [20]. Microglia in the neurodegenerative disease brains are positive for MPO, which is particularly increased in microglia, neurons, and $\beta$-amyloid $(\mathrm{A} \beta)$ plaques and not expressed in quiescent microglia in healthy brains [21,22]. It has been reported that $\mathrm{HOCl}(30-50 \mu \mathrm{mol} / \mathrm{L}$ ) could promote caspase-3 activation, poly (ADP-ribose) polymerase (PARP) degradation, and DNA fragmentation in endothelial cells, indicating there was an involvement of MPO-mediated oxidant [23]. Additionally, PARP1 speeds up inflammatory cytokine secretion in microglia by increasing promoter DNA accessibility via histone ADP-ribosylation [24]. Triggering receptor expressed on myeloid cell 2 (TREM2), specifically expressed by microglia in the brain, modulates microglia to recognize cellular remnants from apoptosis or misfolded proteins [10]. After activation, microglia could polarize into classic inflammatory M1 and immunosuppressive M2 phenotype through regulation by TREM2 [25]. Dysfunctional microglia in frontotemporal dementia (FTD) mouse model might be due to homozygous TREM2 missense mutations such as p.T66M [26]. A rare missense mutation (rs75932628, p. R47H) of the TREM2 gene has been reported as an essential risk factor for AD, FTD, and PD [27,28]. Furthermore, bridging integrator 1 (BIN1) could contribute to tau pathology progression by regulating tau clearance and promoting the release of tau enriched extracellular vesicles by microglia [29]. Single nucleotide polymorphisms (SNPs) in the BIN1 gene, including rs744373 and rs7561528, have been identified to be significantly associated with AD in East Asian and Caucasian populations [30-32]. Although SNPs from BIN1 (rs744373) loci may not play a major role in PD, PD dementia (PDD), or PD-mild cognitive impairment in a Chinese population, SNPs from BIN1 (rs6733839) loci was identified in patients with Lewy body diseases (LBDs) in a Caucasian population [33,34]. As alluded to above, it is still unclear if the altered microglial function is a cause, consequence, or contribution to tau pathology. To further test this, this study investigated TSPO density and tau fibril in the caudate and putamen of postmortem human brains using quantitative autoradiography in Lewy body diseases (LBDs including PD, PDD, and DLB) and $\mathrm{AD}$ brains and compared the results to control groups. Sample concentrations of MPO, poly 
(ADP-ribose) (PAR), and TREM2 were determined via enzyme-linked immunosorbent assay (ELISA). Additionally, all samples were genotyped for TSPO, TREM2, and BIN1 using SNP Assays. Our findings show potential interactions between genotypes and abnormal neurological phenotypes and provide a deep understanding of the microglial function implicated in tauopathy in the striatum of $\mathrm{AD}$ and LBDs.

\section{Results}

\subsection{Baseline Information and Clinical Features of Study Subjects}

In the present study, we collected human brains at autopsy between 3 and $47 \mathrm{hrs}$ postmortem. Table 1 summarizes the baseline information and clinical features of the study participants. There were no significant differences in age at death, PMI, brain weight, onset, and disease progression, indicating that our results were not affected by these factors. There was a significant difference between the AD and control groups in the Braak NFT stage factors.

Table 1. Baseline information and clinical features of the study subjects. PMI: Postmortem Interval; Braak neurofibrillary tangles (NFT) stage: Braak neurofibrillary tangle stage; Braak A $\beta$ stage: Braak amyloid-beta plaque stage. ${ }^{*}$ Indicates $p<0.05$ vs. the controls.

\begin{tabular}{|c|c|c|c|c|c|c|}
\hline & Control & PD & PDD & DLB & $\mathrm{AD}$ & $\mathbf{P}$ \\
\hline Participants & 10 & 10 & 8 & 10 & 27 & \\
\hline Male/Female & $6 / 4$ & $7 / 3$ & $7 / 1$ & $5 / 5$ & $13 / 14$ & NA \\
\hline Age & $83 \pm 2$ & $78 \pm 2$ & $77 \pm 3$ & $81 \pm 2$ & $82 \pm 2$ & NA \\
\hline PMI (h) & $18.8 \pm 5$ & $16.0 \pm 3.2$ & $10.8 \pm 1.6$ & $18.0 \pm 3.7$ & $10.6 \pm 1$ & NA \\
\hline Brain weight (g) & $1326 \pm 60$ & $1299 \pm 40$ & $1346 \pm 41$ & $1273 \pm 38$ & $1127 \pm 47$ & NA \\
\hline Onset & & $65 \pm 3$ & $60 \pm 3$ & $66 \pm 4$ & $71 \pm 2$ & NA \\
\hline Progression & & $14 \pm 1$ & $16 \pm 3$ & $14 \pm 3$ & $10 \pm 1$ & NA \\
\hline Braak NFT stage & $\begin{array}{l}\text { Stage } 0: 1 \\
\text { Stage I:2 } \\
\text { Stage II:4 } \\
\text { Stage III:3 }\end{array}$ & $\begin{array}{l}\text { Stage I:5 } \\
\text { Stage II:2 } \\
\text { Stage III:3 }\end{array}$ & $\begin{array}{l}\text { Stage I:3 } \\
\text { Stage II:2 } \\
\text { Stage III:3 }\end{array}$ & $\begin{array}{l}\text { Stage I:7 } \\
\text { Stage II:2 } \\
\text { Stage V:1 }\end{array}$ & $\begin{array}{l}\text { Stage V:13 } \\
\text { stage VI:14 }\end{array}$ & * \\
\hline Braak $A \beta$ stage & All normal & $\begin{array}{l}\text { Normal:3 } \\
\text { Stage A:1 } \\
\text { Stage B:2 } \\
\text { Stage C:5 }\end{array}$ & $\begin{array}{l}\text { Normal:1 } \\
\text { Stage A:2 } \\
\text { Stage B:1 } \\
\text { Stage C:4 }\end{array}$ & $\begin{array}{l}\text { Normal:1 } \\
\text { Stage A:1 } \\
\text { Stage B:2 } \\
\text { Stage C:6 }\end{array}$ & All stage C & NA \\
\hline L-Dopa response & & $\begin{array}{l}\text { Yes: } 9 \\
\text { Modest:1 }\end{array}$ & $\begin{array}{l}\text { Yes: } 6 \\
\text { Modest:2 }\end{array}$ & $\begin{array}{l}\text { Yes: } 9 \\
\text { Modest:1 }\end{array}$ & & \\
\hline
\end{tabular}

\subsection{TREM2 (rs75932628), TSPO (rs6971), and BIN1 (rs7561528) Genotypes of the Study Subjects}

In total, as shown in Table 2, we identified the TREM2 (rs75932628), TSPO (rs6971), and BIN1 (rs7561528) genotypes of 65 subjects (10 PD, 8 PDD, 10 DLB, 27 AD, and 10 age-matched controls). Although rs75932628 in TREM2 was believed to be the risk for Alzheimer's and Parkinson's disease $[28,35]$, this specific variant of the TREM2 gene was not identified in the disease or control groups. The frequency of disease groups that carry the TSPO (rs6971) functional polymorphism (AG genotype) was higher than that of the control group. The highest frequency of the AG genotype was found in PDD patients. Additionally, a lower frequency of the conserved/ancestral variant (GG) was observed in the disease groups than controls, especially in PDD. The controls were split fairly among the BIN1 gene SNP (GG) and (AG), that is $50 \%$ per allele. The highest ratio of GG carriers was found in DLB, and the highest ratio of AG carriers was found in PD when compared to controls. 
However, the small sample sizes limited the ability to detect significant differences in the distributions of the TSPO and BIN1 polymorphisms.

Table 2. Detection of TSPO and BIN1 single nucleotide polymorphisms (SNPs) genotype (AA, GG, and $\mathrm{AG})$ in 65 neurodegenerative disease patients with the absence of TREM2 gene variants. There are two samples, from the Parkinson's disease (PD) and dementia with Lewy bodies (DLB) groups, that clustered oddly for the BIN1 (rs7561528).

\begin{tabular}{|c|c|c|c|c|c|c|c|c|c|c|c|c|}
\hline \multirow{3}{*}{$\begin{array}{l}\text { Group } \\
\text { Controls }\end{array}$} & \multicolumn{6}{|c|}{ TSPO (rs6971) Genotype } & \multicolumn{6}{|c|}{ BIN1 (rs7561528) Genotype } \\
\hline & \multicolumn{2}{|c|}{ AA } & \multicolumn{2}{|c|}{ GG } & \multicolumn{2}{|c|}{ AG } & \multicolumn{2}{|c|}{ AA } & \multicolumn{2}{|c|}{ GG } & \multicolumn{2}{|c|}{ AG } \\
\hline & 2 & $20 \%$ & 5 & $50 \%$ & 3 & $30 \%$ & & & 5 & $50 \%$ & 5 & $50 \%$ \\
\hline PD & 2 & $20 \%$ & 4 & $40 \%$ & 4 & $40 \%$ & & & 4 & $44.4 \%$ & 5 & $55.6 \%$ \\
\hline PDD & & & 3 & $37.5 \%$ & 5 & $62.5 \%$ & 1 & $12.5 \%$ & 4 & $50 \%$ & 3 & $37.5 \%$ \\
\hline DLB & 2 & $20 \%$ & 4 & $40 \%$ & 4 & $40 \%$ & 1 & $11.1 \%$ & 5 & $55.6 \%$ & 3 & $33.3 \%$ \\
\hline $\mathrm{AD}$ & 2 & $7.4 \%$ & 12 & $44.4 \%$ & 13 & $48.2 \%$ & 2 & $7.4 \%$ & 11 & $40.7 \%$ & 14 & $51.9 \%$ \\
\hline $\begin{array}{c}\text { Chi-square, } \mathrm{df} \\
\quad p \text { value }\end{array}$ & & & & $\begin{array}{l}17,8 \\
9055\end{array}$ & & & & & & $\begin{array}{l}97,4 \\
947\end{array}$ & & \\
\hline
\end{tabular}

\subsection{Myeloperoxidase (MPO) Levels in the Caudate and Putamen of the Different Groups}

We performed an ELISA assay following the protocol mentioned in the methods section to ascertain MPO levels in the caudate and putamen of the disease groups and age-matched controls. Surprisingly, as shown in Figure 1a, the quantification of brain MPO levels reveals a substantial overlap between disease and healthy control subjects. However, no statistical significance was found across different groups.

When stratified by BIN1 (rs7561528) genotype (Figure 1b,c), the G allele on putamen MPO levels may increase the risk of DLB for patients. Patients who carried BIN1 with homogenous GG showed a $132.5 \%$ increase in MPO levels compared to heterozygous AG carriers $(p=0.0564)$. One outlying sample found in the PD group was identified as an AG carrier (Figure 1b), and it contained the highest MPO levels of all the samples for both the caudate and putamen.

Spearman analyses revealed significant positive correlations between MPO and PAR concentrations in the putamen of both AD patients with the TSPO (rs6971) GG genotype $\left(r_{\mathrm{s}}=0.806, p=0.005\right)$ and PDD patients with the TSPO (rs6971) AG genotype $\left(r_{\mathrm{s}}=0.900, p=0.037\right)$ (Figure 1d). The above findings provide further evidence that poly (ADP-ribose) synthesis is induced by $\mathrm{H}_{2} \mathrm{O}_{2}$ and modulated by MPO [36]. 
(a)

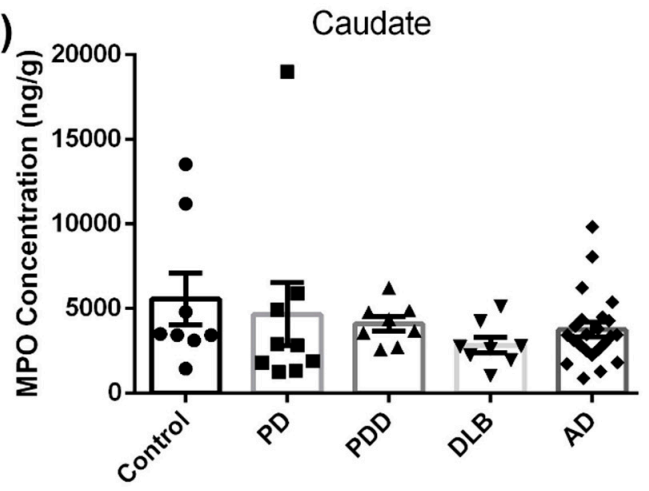

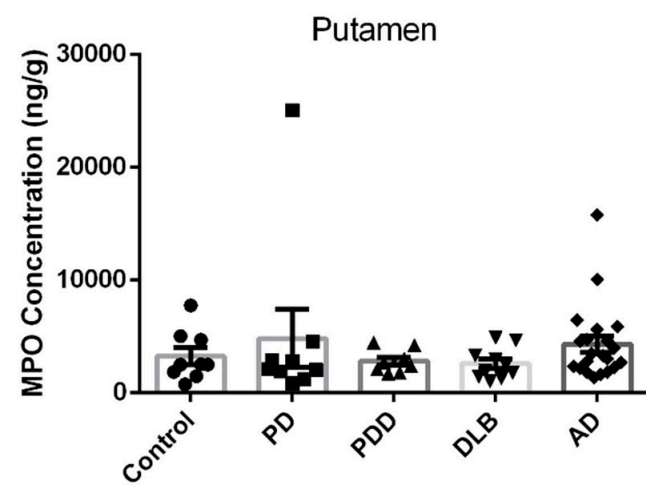

(b)
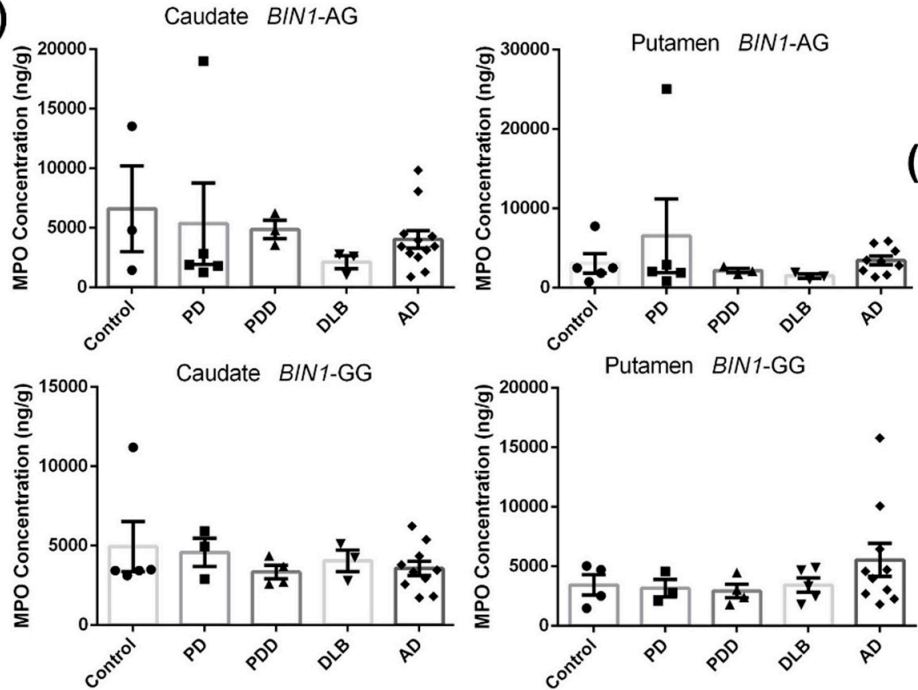

Putamen BIN1-GG

(c) DLB-Putamen is BIN1 genotype

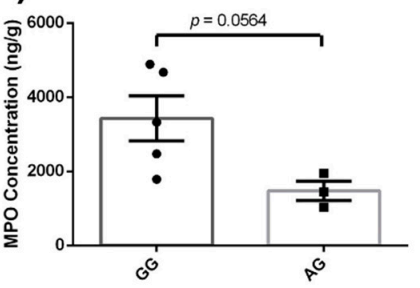

(d)

AD-Putamen TSPO-GG

PDD-Putamen TSPO-AG
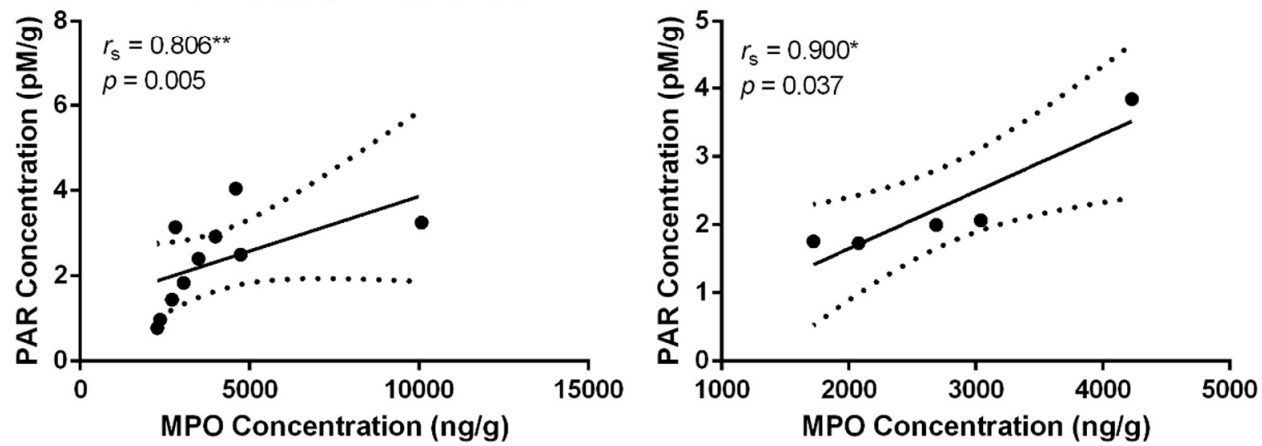

Figure 1. Myeloperoxidase (MPO) levels in the caudate and putamen from patients in disease groups (PD: $n=10$, PD dementia (PDD): $n=8$, DLB: $\mathrm{n}=10$, Alzheimer's disease (AD): $n=27$ ) and age-matched controls $(n=10)$. (a): Quantitative analysis of the concentrations of MPO in the caudate and putamen from subjects. Values shown are means \pm SEM. $(\mathbf{b})$ : Concentrations of MPO in the caudate and putamen from BIN1-AG and BIN1-GG carriers. Values shown are means \pm SEM. (c): The BIN1 rs7561528 SNP impact the concentrations of MPO in the putamen of DLB patients, $p=0.0564$. Values shown are means \pm SEM. (d): Correlations of MPO vs. Poly (ADP-ribose) (PAR). $r_{\mathrm{s}}$, the Spearman's rank correlation coefficient. A $p$-value of $<0.05$ was considered significant: * indicates $p<0.05,{ }^{* *}$ indicates $p<0.01$.

\subsection{Poly (ADP-ribose) (PAR) Levels in the Caudate and Putamen of the Different Groups}

An ELISA assay was performed to determine the PAR concentrations in the caudate and putamen samples taken from the disease groups and age-matched controls, as shown in Figure 2a. We found that the levels of PAR in the caudate of LBDs decreased significantly compared to AD cases (PD: $-75 \%, p=$ 0.0441 ; PDD: $-72.3 \%, p=0.0568$; DLB: $-84.8 \%, p=0.0294$ ). The results in the putamen vastly differed 
from the caudate. In the putamen, the levels of PAR in disease groups were comparable to the controls except for a small non-significant reduction in AD cases (Control: $3.475 \pm 1.253$; PD: $3.064 \pm 0.5305$; PDD: $2.336 \pm 0.639$; DLB: $2.627 \pm 0.3691$; AD: $2.166 \pm 0.2415)$. Similar changes in PAR concentrations in the caudate and putamen are in line with our previous 8-oxo-dG levels with equivalent samples taken from the same study subjects [19].

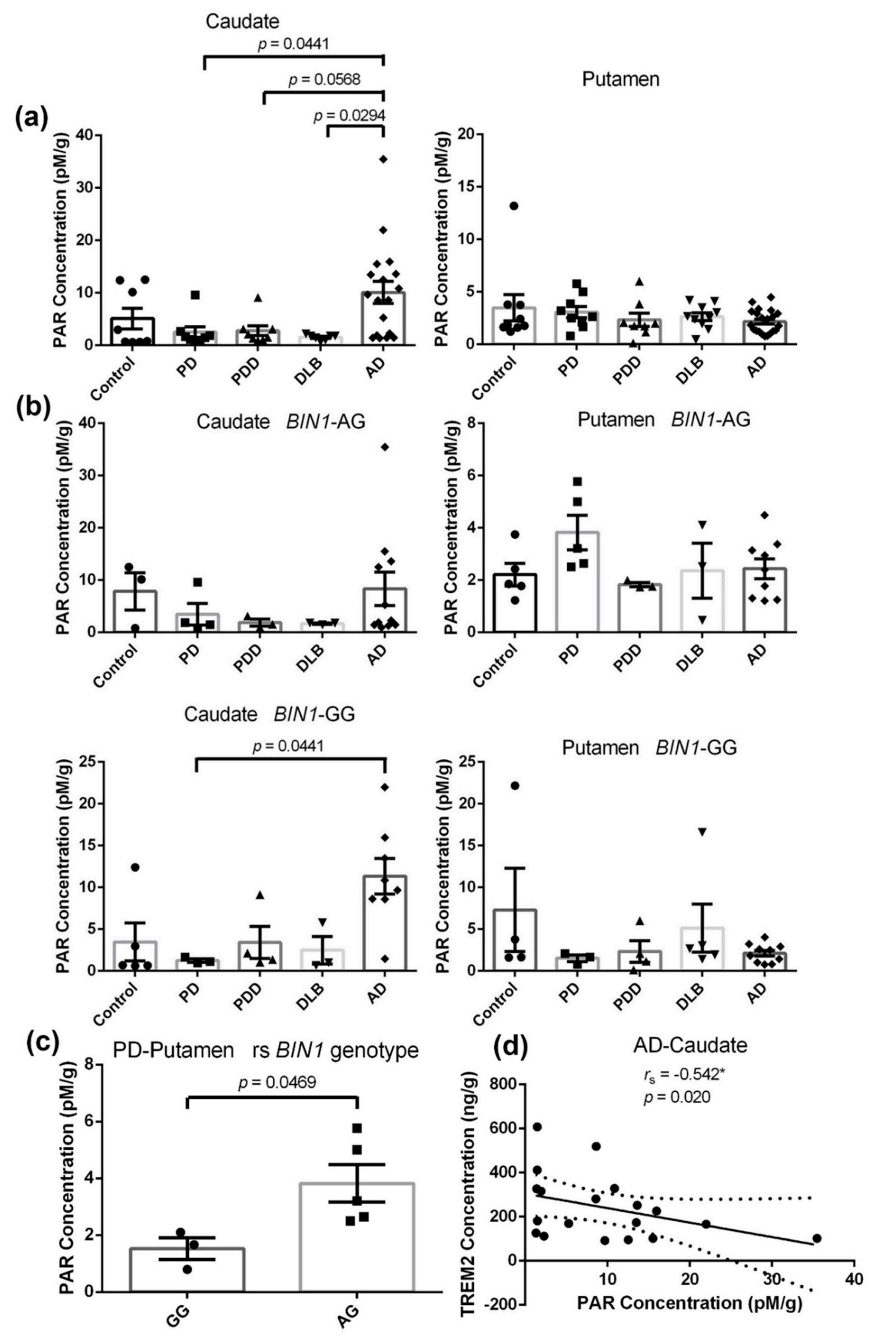

Figure 2. PAR levels in the caudate and putamen from patients in disease groups (PD: $n=10$, PDD: $n=$ 8, DLB: $n=10$, AD: $n=27)$ and age-matched controls $(n=10)$. (a): Quantitative analysis of the 
concentrations of PAR in the caudate and putamen from subjects. Values shown are means \pm SEM. Statistical significances between two disease groups are indicated with brackets and corresponding $p$-values. (b): Concentrations of PAR in the caudate and putamen from BIN1-AG and BIN1-GG carriers. Values shown are means \pm SEM. Statistical significance between two disease groups is indicated with brackets and corresponding $p$-values. (c): The BIN1 rs7561528 SNP impact the concentrations of PAR in the putamen of PD patients. Values shown are means \pm SEM. Statistical significance between two disease groups is indicated with brackets and corresponding $p$-values. (d): Correlations of PAR vs. TREM2. $r_{\mathrm{s}}$, the Spearman's rank correlation coefficient. A $p$-value of $<0.05$ was considered significant: * indicates $p<0.05$.

The discovery that the rs7561528 SNP in the BIN1 gene is associated with significantly variable PAR levels in the PD groups has provided us with a better understanding of relevant biological events. The allele G of the BIN1 gene shows a region-specific impact on PAR variance, as shown in Figure $2 b$. The highest putamen PAR concentration was found in the PD patients carrying the heterozygous AG genotype (Control: $2.208 \pm 0.4305$; PD: $3.825 \pm 0.6595$; PDD: $1.828 \pm 0.0846$; DLB: $2.362 \pm 1.053$; AD: $2.434 \pm 0.3816)$. Conversely, the lowest putamen PAR concentration was found in the PD patients carrying the homozygous GG genotype (Control: $7.306 \pm 4.984$; PD: $1.524 \pm 0.383$; PDD: $2.339 \pm 1.284$; DLB: $5.137 \pm 2.876$; AD: $2.125 \pm 0.3636$ ). Compared to AG carriers in the PD group, the level of PAR in the putamen was significantly decreased by $60.2 \%$ for these homozygous GG carriers $(p=0.0469)$ (Figure 2c).

Additionally, the concentration of PAR showed a significant positive correlation with TREM2 expression in the caudate of AD brains (Figure $2 \mathrm{~d}, r_{\mathrm{s}}=-0.542, p=0.020$ ), which potentially explained the hypothesis that poly (ADP-ribose) polymerase-1 (PARP-1) modulate microglial phenotypes [37].

\subsection{Triggering Receptor Expressed on Myeloid Cell 2 (TREM2) Expressions in the Caudate and Putamen of the Different Groups}

TREM2 is a type I transmembrane receptor uniquely expressed on the microglial membrane $[38,39]$. We quantitatively assessed the striatal TREM2 expressions of the disease groups and age-matched controls using ELISA assay, as shown in Figure 3a. TREM2 levels in the caudate and putamen of disease patients and controls did not significantly differ due to large natural variabilities in each group. We observed trends of increasing and decreasing TREM2 expressions in the caudate and putamen of the LBDs, respectively.

When the data were stratified by BIN1 (rs7561528) genotypes compared to the controls, we found a meaningful effect of the allele $G$ of the BIN1 gene on TREM2 expressions in caudate of the DLB patients (Figure 3b). Individuals carrying homozygous GG showed higher TREM2 levels than heterozygous AG carriers (Figure 3c, increased by $102.5 \%, p=0.0535$ ).

Looking at the correlation between the concentration of TREM2 and tau fibrils more closely, we see a significant negative association between TREM2 expression and tau fibrils in the putamen of patients with DLB $\left(r_{\mathrm{s}}=-0.667, p=0.050\right)$, as shown in Figure 3d. Changes in microglial phenotypes might help to provide a better understanding of this interaction. Additionally, the concentration of TREM2 showed a significant positive correlation with the MPO level in the caudate of AD patients identified as rs BIN1 GG genotype $\left(r_{\mathrm{s}}=0.685, p=0.029\right)$, which is in keeping with the hypothesis that TREM2 is involved in increased neutrophil infiltration [40]. Surprisingly, TREM2 levels in the putamen of LBDs were found to increase with the disease progression (Figure $3 \mathrm{~d}, r_{\mathrm{s}}=0.501, p=0.013$ ). The correlations between disease progression and TREM2 level in the putamen of PDD patients (Figure S3, $r_{\mathrm{S}}=0.786, p$ $=0.036$ ), as well PD stage and TREM2 level in the putamen of LBDs (Figure $S 4, r_{\mathrm{S}}=0.421, p=0.036$ ) further supported the association between microglial phenotype and disease progression [41]. 
(a)

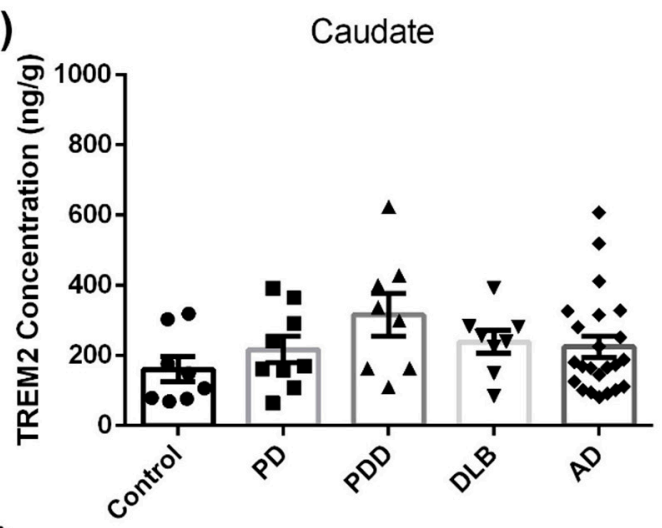

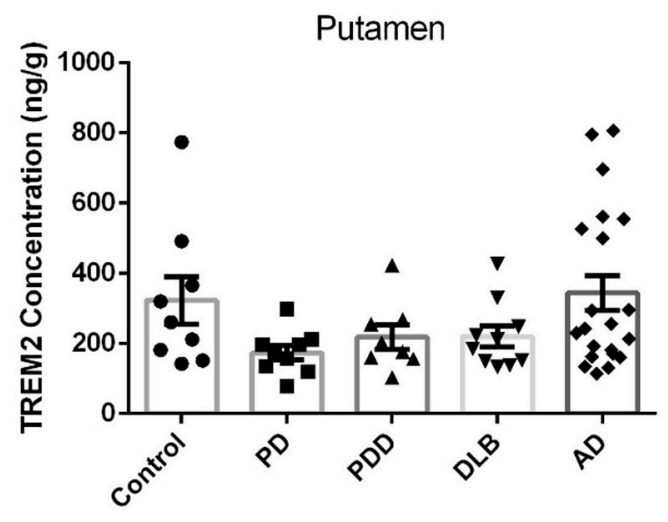

(b)
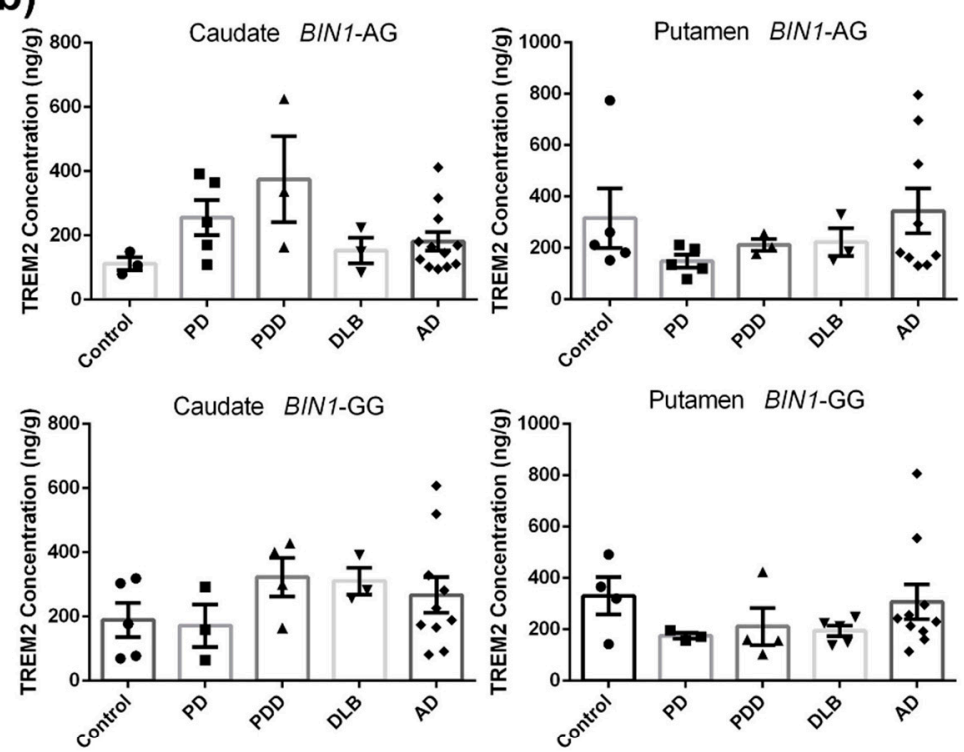

Putamen BIN1-GG

(c)

DLB-Caudate rs BIN1 genotype
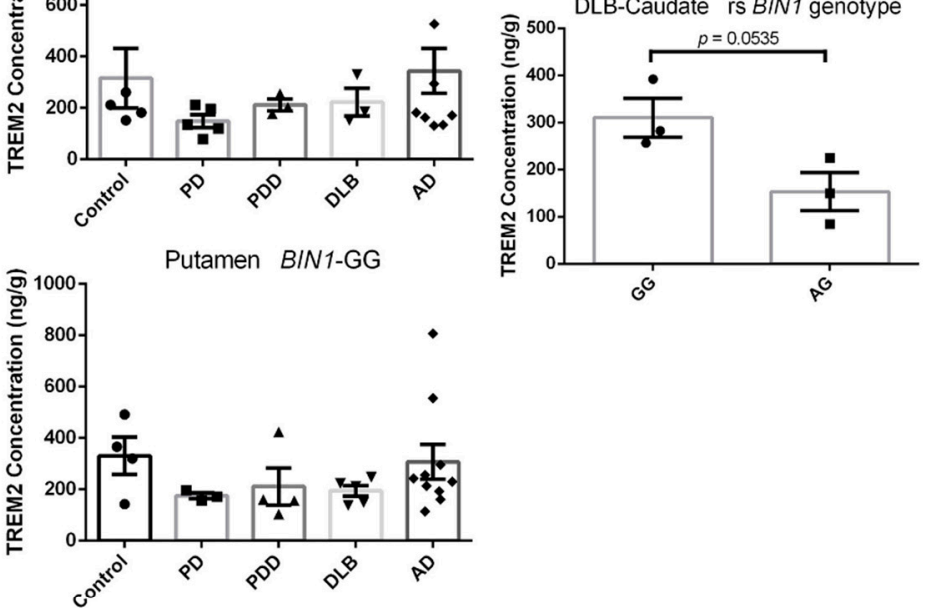

(d)

AD-Caudate BIN1-GG
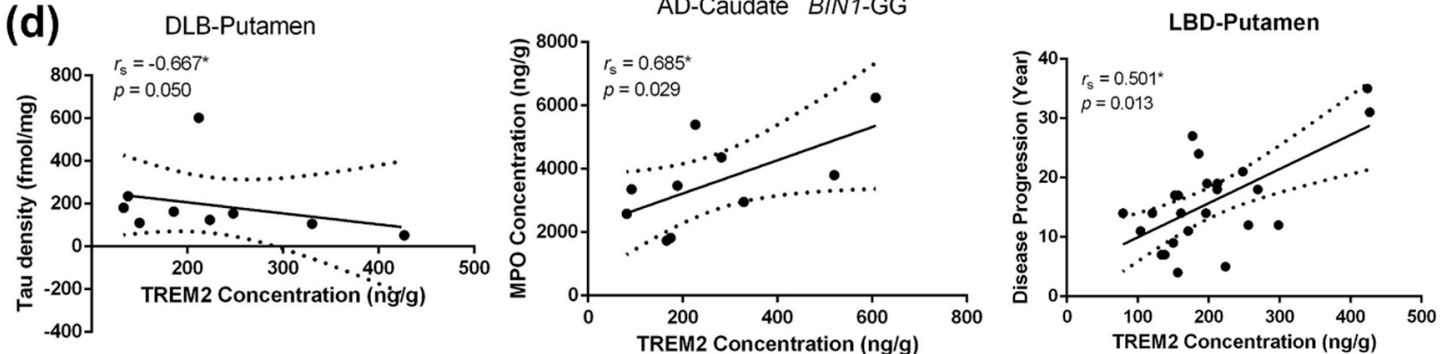

Figure 3. TREM2 levels in the caudate and putamen from patients in disease groups (PD: $n=10$, PDD: $n=8$, DLB: $n=10$, AD: $n=27)$ and age-matched controls $(n=10)$. (a): Quantitative analysis of the concentrations of TREM2 in the caudate and putamen from subjects. Values shown are means \pm SEM. (b): Concentrations of TREM2 in the caudate and putamen from BIN1-AG and BIN1-GG carriers. Values shown are means \pm SEM. (c): The BIN1 rs7561528 SNP impact the concentrations of TREM2 in the caudate of DLB patients, $p=0.0535$. Values shown are means \pm SEM. (d): Correlations of TREM2 vs. Tau, TREM2 vs. MPO, and TREM2 vs. Disease Progression. $r_{\mathrm{s}}$, the Spearman's rank correlation coefficient. A $p$-value of $<0.05$ was considered significant: * indicates $p<0.05$.

\subsection{8-kDa Translocator Protein (TSPO) Density in the Caudate and Putamen of the Different Groups}

TSPO expression is correlated with the extent of microglial activation. We determined the striatal TSPO densities of the disease groups and age-matched controls using quantitative autoradiography. In comparison with controls, lower levels of striatal TSPO binding were obtained in the caudate (PD: -75.7\%, PDD: $-63.1 \%$, DLB: $-69.2 \%$ ) and putamen (PD: $-67.4 \%$, PDD: $-57.5 \%$, DLB: $-68.9 \%$ ) samples 
of LBDs, as shown in Figure 4a, statistically significant results were obtained for the LBDs when compared with AD cases. Conversely, slight increases in TSPO densities of both the caudate (37.0\% increase) and the putamen (27.4\% increase) of AD cases were found in this study; however, statistical significance was not reached when compared to the controls.

Caudate

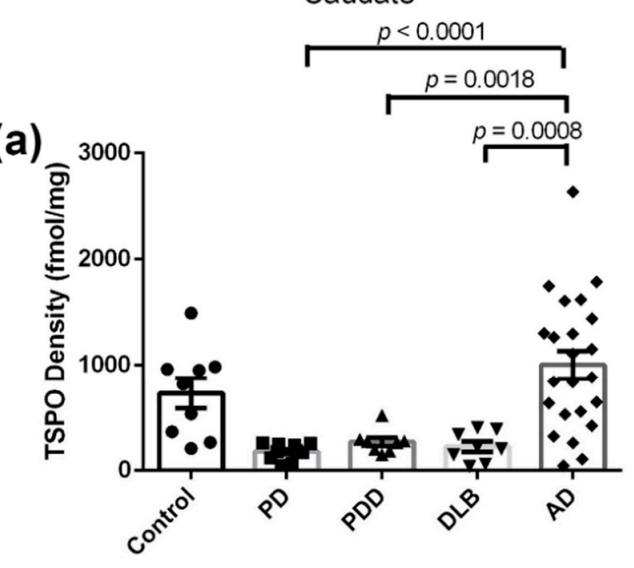

Putamen

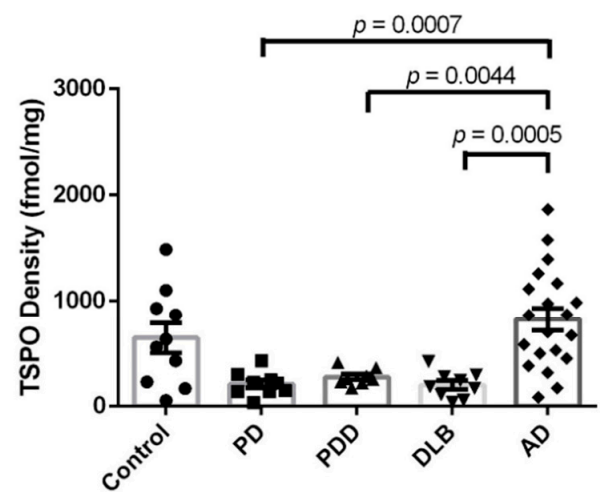

(b)

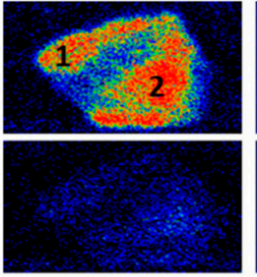

Control

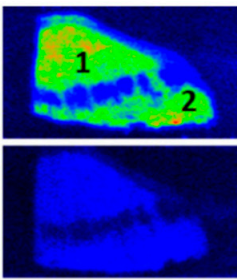

PD

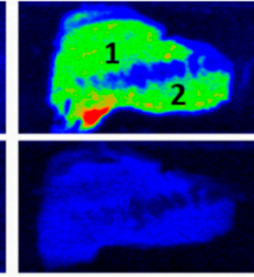

PDD

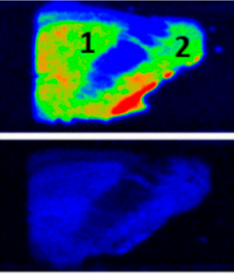

DLB

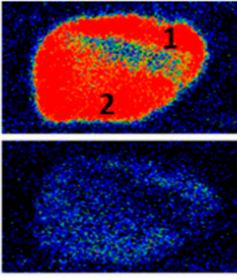

AD

(c) $\mathrm{nCi} / \mathrm{mg}$

(d) o \begin{tabular}{llllllllll|l}
0.14 & 0.29 & 0.54 & 1.04 & 2 & 3.7 & 8 & 16.6 & 36.3
\end{tabular}

rS TSPO genotype

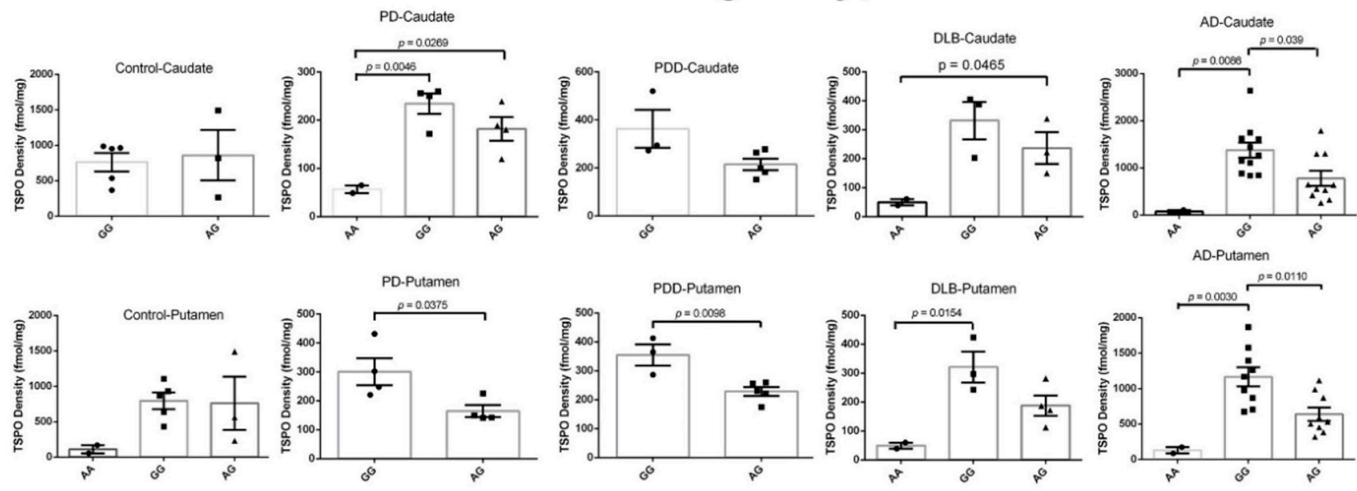

(e)
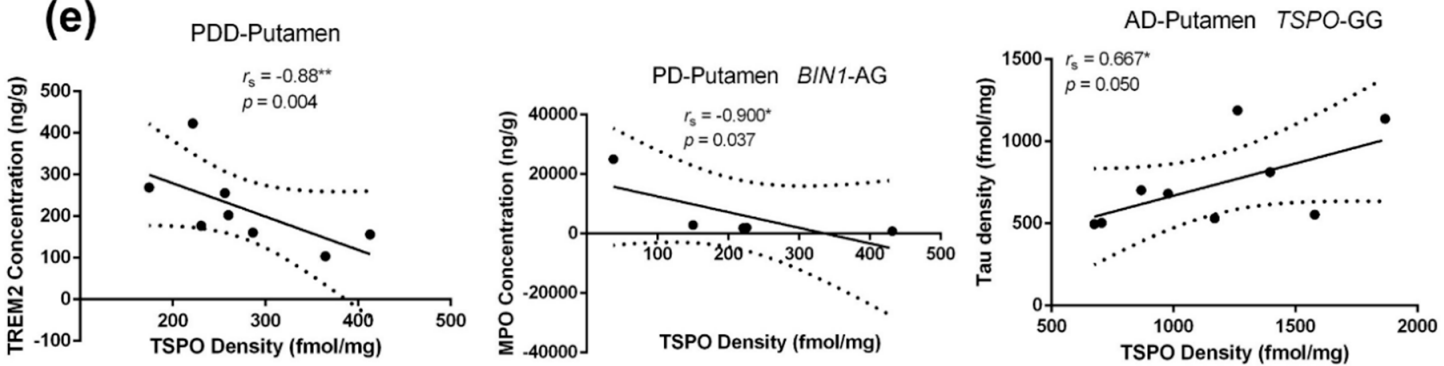

Figure 4. TSPO densities in the caudate and putamen of patients in the disease groups (PD: $n=10$, PDD: $n=8$, DLB: $n=10$, AD: $n=27)$ and age-matched controls $(n=10)$. (a): Quantitative analysis of 
the TSPO densities (fmol/mg) in the caudate and putamen from subjects. Values shown are means \pm SEM. Statistical significances between two disease groups are indicated with brackets and corresponding $p$-values. (b) Autoradiograms show total binding of $2 \mathrm{nmol} / \mathrm{L}\left[{ }^{3} \mathrm{H}\right] \mathrm{PBR} 28$ (Panel B top row) and nonspecific binding in the presence of $1 \mu \mathrm{M}$ PK11195 (Panel B bottom row) in the striatal regions of 5 representative subjects. The numbers 1 and 2 designate the following regions: (1) caudate and (2) putamen. (c): $\left[{ }^{3} \mathrm{H}\right]$ Microscale standards (ranging from 0 to $36.3 \mathrm{nCi} / \mathrm{mg}$ ) were counted alongside samples. (d) The TSPO rs6971 SNPs impacts the density of TSPO in the caudate and putamen from patients with the disease. Values shown are means \pm SEM. Statistical significances between two disease groups are indicated with brackets and corresponding $p$-values. (e): Correlations of TSPO vs. TREM2, TSPO vs. MPO, and TSPO vs. Tau. $r_{\mathrm{s}}$, the Spearman's rank correlation coefficient. A $p$-value of $<0.05$ was considered significant: ${ }^{*}$ indicates $p<0.05,{ }^{* *}$ indicates $p<0.01$.

We observed that the TSPO rs6971 SNP significantly impacted on the TSPO levels in the caudate and putamen of disease groups (Figure 4d). We genotyped the TSPO rs6971 SNP in 65 subjects (PD: $n$ =10, PDD: $n=8$, DLB: $n=10$, AD: $n=27$ ) and we interrogated differential TSPO levels across this SNP. Significant differences between homozygous GG and heterozygous AG were identified in the putamen of PD, PDD, and AD brains and the caudate of AD cases. No differences were noticed in the controls. TSPO levels in the putamen of homozygous GG carriers were significant higher than heterozygous AG carriers, especially for PD (increased by $82.7 \%, p=0.0075$ ), PDD (increased by 55.2\%, $p=0.0098$ ), and $\mathrm{AD}$ (increased by $82.5 \%, p=0.0110$ ). Similar increases were observed in the caudate: TSPO levels in AD patients carrying TSPO with homozygous GG genotype showed higher TSPO expressions than heterozygous AG carriers (increased by $77.1 \%, p=0.0039$ ).

As shown in Figure 4e, Spearman analyses revealed negative correlations between TSPO density and TREM2 concentration in the putamen of PDD brains $\left(r_{\mathrm{S}}=-0.88, p=0.004\right)$, as well as TSPO density and MPO concentration in the putamen of the PD patients carrying BIN1 with heterozygous AG $\left(r_{\mathrm{s}}=-0.900, p=0.037\right)$. We found obvious positive correlations between TSPO densities and the concentration of tau fibrils in the putamen of AD patients carrying TSPO with homozygous GG $\left(r_{\mathrm{s}}=0.667, p=0.050\right)$, which supports the hypothesis that microglia are involved in the pathological spread of tau [7].

\subsection{Tau Fibrils in the Caudate and Putamen of the Different Groups}

We measured tau fibrils of the disease groups and age-matched controls using quantitative autoradiography with $\left[{ }^{3} \mathrm{H}\right] \mathrm{MK} 6240$. As shown in Figure 5a, the distribution of tauopathy in the striatal regions was abundant, and no regional differences in binding were found in either the caudate or putamen of the controls (caudate: $457.6 \pm 82.6$; putamen: $489.3 \pm 91.53$ ). Surprisingly, substantial tau fibril reductions with statistical significance were found for the caudate $(p<0.0001$ vs. AD: PD: $-73.8 \%$; PDD: $-71.8 \%$; DLB: $-60.3 \%$ ) and putamen of LBDs (PD: $-75.2 \%, p=0.0011$; PDD: $-72.6 \%, p=$ 0.0026; DLB: $-56.5 \%, p=0.0176$ ) when compared to controls. In comparison with controls, significant increases of tau densities were found for the putamen of AD cases (increased by 46.4\%, $p=0.0213$ ). No statistical significance was found in the caudate of AD compared to controls due to large natural variance in these cohorts.

Interestingly, as shown in Figure 5d, Spearman analyses revealed positive correlations between the concentration of tau fibrils and MPO in the caudate of DLB patients $\left(r_{\mathrm{S}}=0.821, p=0.023\right)$ and in the putamen of DLB patients $\left(r_{\mathrm{s}}=0.65, p=0.058\right)$. Furthermore, Spearman analyses uncovered significant positive correlations between the concentration of tau fibrils and MPO in the putamen of the AD patients with the TSPO (rs6971) AG genotype $\left(r_{\mathrm{s}}=0.700, p=0.036\right)$ and the caudate of PD patients with the BIN1 (rs7561528) AG genotype $\left(r_{\mathrm{s}}=0.900, p=0.037\right)$. These results shed light on how the misfolded tau is involved in redox imbalance [42]. 
Caudate

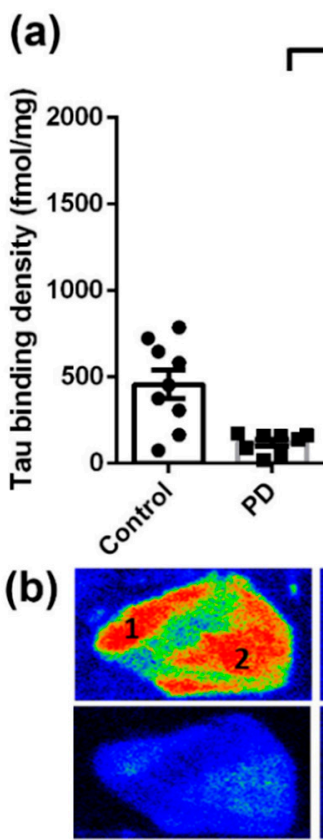

Control $p<0.0001$

$p<0.0001$

$p<0.0001$

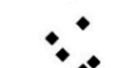

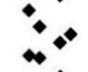
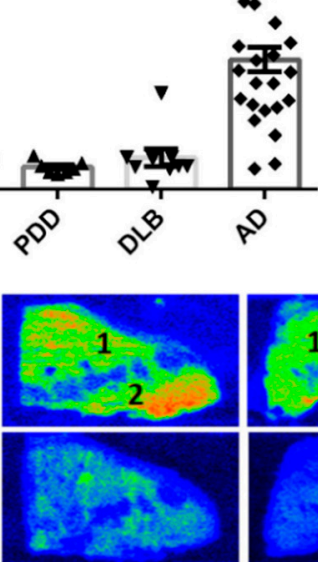

PD

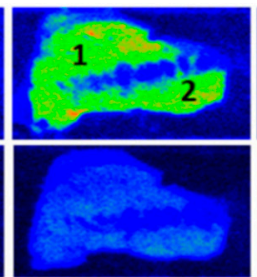

PDD
Putamen

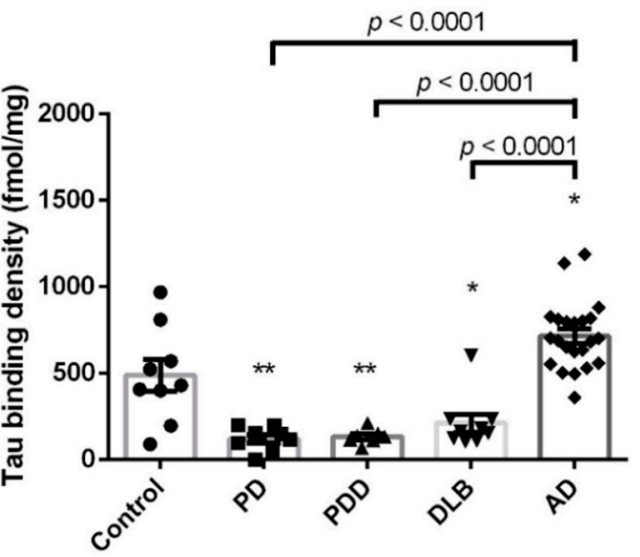

(c) $\mathrm{nCl} / \mathrm{mg}$

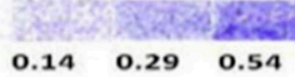

(d) DLB-Caudate
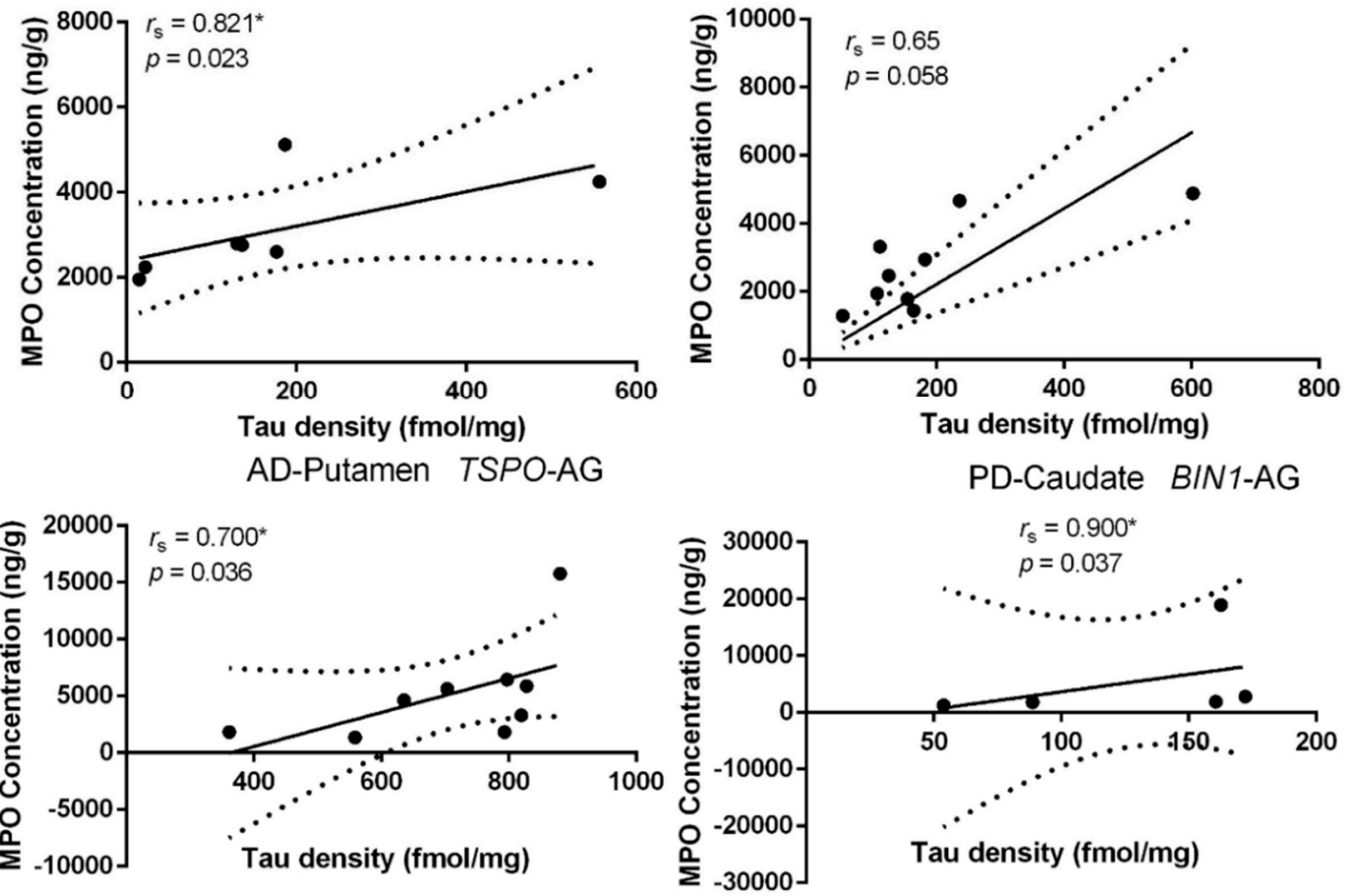

Figure 5. Tau fibrils in the caudate and putamen from patients in disease groups (PD: $n=10$, PDD: $n=8$, DLB: $n=10$, AD: $n=27)$ and age-matched controls $(n=10)$. (a): Quantitative analysis of the Tau density (fmol/mg) in the caudate and putamen from subjects. Values shown are means \pm SEM. Statistical significances between two disease groups are indicated with brackets and corresponding $p$-values. A $p$-value of $<0.05$ was considered significant: ${ }^{*}$ indicates $p<0.05$, ${ }^{* *}$ indicates $p<0.01$, vs. controls. (b) Autoradiograms show total binding of $2 \mathrm{nmol} / \mathrm{L}\left[{ }^{3} \mathrm{H}\right] \mathrm{MK} 6240$ (Panel B top row) and 
nonspecific binding in the presence of $10 \mu \mathrm{M}$ T807 (Panel B bottom row) in the striatal regions of 5 representative subjects. The numbers 1 and 2 designate the following regions: (1) caudate and (2) putamen. (c): $\left[{ }^{3} \mathrm{H}\right]$ Microscale standards (ranging from 0 to $36.3 \mathrm{nCi} / \mathrm{mg}$ ) were counted alongside samples. (d) Correlations between Tau and MPO. $r_{s}$, the Spearman's rank correlation coefficient. A $p$-value of $<0.05$ was considered significant: * indicates $p<0.05$.

\section{Discussion}

Interest in microglia and the role of neuroinflammation in neurodegenerative diseases is gaining momentum. Because of the discrepancies between various genetic models used to study the TSPO gene in mice, this study has investigated the interactions between oxidative damage, microglia, and tauopathy in humans without losing sight of the importance of single nucleotide polymorphisms.

\subsection{TREM2 (rs75932628), TSPO (rs6971), and BIN1 (rs7561528) Genotypes of the Study Subjects}

A rare missense mutation (rs75932628, p.R47H) in the TREM2 gene has been reported to crucially increase the risk of developing $\mathrm{AD}$ and $\mathrm{PD}[27,28]$. However, we were not able to replicate the positive association between the rs75932628 variant and disease risk in the cohort we studied. The TSPO and BIN1 variants were identified with a statistically non-significant distribution, which might be partially attributed to a small sample size. The rs75932628 variant of the TREM2 gene was also not identified in a Chinese population with PD, multiple system atrophy (MSA), and amyotrophic lateral sclerosis (ALS) $[43,44]$.

A mutation (rs6971) in the TSPO gene-the substitution of threonine for alanine at position 147 of TSPO—could alter the tertiary structure of the protein [45] and exert several biological effects [46,47]. The TSPO (rs6971) SNP has been described as having no impact on cortical TSPO mRNA or protein levels in patients with AD [48]. Contrarily, we found a tight linkage between polymorphisms and variance of TSPO levels in the caudate and putamen of PD, PDD, and AD patients. These data indicate that the TSPO level is haplotype dependent, where TSPO homozygous GG carriers have significantly higher TSPO levels than heterozygous AG carriers-especially in the putamen (PD 82.7\%, PDD 55.2\%, and $\mathrm{AD} 82.5 \%$ ). Considering no differences were observed in age-matched controls (Figure 4d), we cannot simply ascribe the TSPO level alterations to the different binding affinity induced by the TSPO polymorphism (rs6971) [49,50]. Upon microglial activation in the disease pathogenesis, TSPO may experience polymerization leading to the formation of multiple possible binding sites [51]. TSPO functional polymorphisms (AG and AA genotypes) may contribute to neuroprotective mechanisms and reduce immune function [52]. Further investigation into understanding the association of TSPO gene SNPs and TSPO expression, and these results need to be replicated in a larger population.

BIN1 could generate tau pathology development, altering tau clearance, and promoting the release of tau enriched extracellular vesicles by microglia [29]. BIN1-associated SNPs show the strongest association with $\mathrm{AD}$ found and are second only to Apolipoprotein E (APOE) [53]. We discovered the correlation between the BIN1 (rs7561528) SNP and expression levels with MPO, TREM2, and PAR. Among patients with LBDs, homozygous GG carriers show higher MPO and TREM2 levels than heterozygous AG carriers, and the inverse was observed for PAR levels. Our results potentially explain the hypothesis that the rs7561528 A allele may be a protective factor against pathology changes and that the G allele of the BIN1 gene is a possible risk factor for AD [32].

\subsection{Interaction of Reactive Oxygen Species and Microglia in the Caudate and Putamen from Patients with Neurodegenerative Diseases and Age-Matched Controls}

Oxidative damage is a hallmark of the aging brains. MPO is a part of the armamentarium of the innate immune system and can be released from vesicles as neutrophils and monocytes [54]. After the release, MPO catalyzes the reactions between hydrogen peroxide $\left(\mathrm{H}_{2} \mathrm{O}_{2}\right)$ and halides $\left(\mathrm{Cl}^{-}, \mathrm{Br}^{-}\right.$, $\left.\mathrm{I}^{-}\right)$or pseudohalides $\left(\mathrm{SCN}^{-}\right)$, yielding the corresponding hypohalous acids-potential oxidants $[55,56]$. MPO binds to microglia resulting in the secretion of ROS and phagocytosis of microglia to remove 
apoptotic cells and cellular debris, thus promoting additional MPO [57]. In AD, elevated MPO levels have been reported to be localized in senile plaques and some activated microglia of the frontal cortex [58]. However, the more unexpected finding was that no significant MPO alterations could be detected in the striatum (caudate or putamen) of different groups. Consistent with our data, there were no significant differences in MPO in the striatum or cerebellum between PD patients and controls; additionally, the motor cortex of ALS patients does not express higher MPO levels [59]. Thus, these data suggest that brain MPO expression is a generic component of disease or aging-related chronic gliosis rather than a particular etiology [59].

It was surprising to find significant positive correlations between the concentration of tau fibrils and MPO in the DLB cases, AD patients with the heterozygous mutation in TSPO, and PD patients with the heterozygous mutation in BIN1. This finding suggests that misfolded and truncated tau proteins preferentially promote the accumulation of aqueous phase oxidants and free radicals $\left(\mathrm{H}_{2} \mathrm{O}_{2}\right.$, $\bullet \mathrm{OH}$, and $\mathrm{O}_{2}{ }^{\bullet-}$ ), probably activating microglia $[42,60]$. TSPO and BIN1 heterozygous mutations might, to a certain extent, facilitate ROS accumulation mediated by tau fibril, but this needs to be elucidated in further studies.

We uncovered positive correlations between MPO levels and PAR concentrations in the putamen of both AD patients with the homozygous GG mutation in TSPO and PDD patients with the heterozygous AG mutation in TSPO. PAR synthesis was induced by $100 \mu \mathrm{M} \mathrm{H}_{2} \mathrm{O}_{2}$ in the lymphoblastoid Raji cells [36] and is dependent on the number of damaged DNA sites [61]. We question whether the TSPO null mutation AA could play a neuroprotective role against MPO-related damages to DNA.

In humans, upon recognizing DNA strand breaks, ADP-ribosylation is mainly catalyzed by PAR, using nicotinamide adenine dinucleotide $\left(\mathrm{NAD}^{+}\right)$as the donor, to link single or multiple ADP-ribose moieties to nuclear targets [62]. This mechanism plays critical roles in DNA repair, replication, and transcription reactions [63]. PAR levels in PD patients have been described as elevated in the substantia nigra and the cerebrospinal fluid (CSF) [64]. However, our previous studies suggest lower/higher DNA adducts levels in the caudate of advanced LBDs/AD [19] and corresponding PAR levels were observed in the same samples studied. The metabolism and amount of dopamine are instrumental in promoting nucleic oxidation as a major source of ROS. The main differences between LBDs and AD lie in the neural substrates with dopamine metabolism being the significant neurochemical difference [65]. BIN1 heterozygous AG mutation carriers in the PD group showed a higher PAR level in the putamen than homozygous GG carriers, suggesting that the BIN1 (rs7561528) A allele might be a neuroprotective factor against advanced disease progression.

A significant negative correlation was found between the PAR concentrations and TREM2 expressions in the caudate of AD patients $\left(r_{\mathrm{s}}=-0.542, p=0.020\right)$, most likely because one of the molecular switches, PARylation, may be responsible for transiting microglia towards the inflammatory phenotype $[24,37,66]$.

TREM2 is a transmembrane receptor of the immunoglobulin superfamily predominantly expressed on microglia in the brain [8]. TREM2 expression on microglia cells correlates with a specific activated microglial phenotype and helps to switch between the classic inflammatory M1 and immunosuppressive M2 phenotypes [67]. Different stages of disease-associated-microglia were regulated independently/dependently by TREM2, indicating high microglial heterogeneity in individual patients during the disease progression [41]. Correlations between TREM2 levels and disease progression/PD stage strongly supported this hypothesis (Figure 3d, Figure S3 and Figure S4). Several studies have shown higher TREM2 levels in the midbrain of PD mice [25] and TREM2 highly expressed in microglia of AD brains or AD model mice [38,68]. We observed trends of increasing and decreasing TREM2 expressions in the caudate and putamen of the LBDs without statistical significance. Compared to decreased TSPO levels in the caudate of patients with LBDs, the increase of TREM2 in this brain region seems to be a compensatory attempt of TREM2 to attenuate the excessive microglial over-activation or ameliorate non-responsive microglial types [25]. 
Further evidence for this explanation can be found in the negative correlation between TREM2 concentrations and TSPO densities in the putamen of the PDD patients $\left(r_{\mathrm{s}}=-0.88, p=0.004\right)$. DLB patients carrying the homozygous BIN1 (rs7561528) GG mutation showed remarkably higher TREM2 levels in the caudate than the heterozygous AG carriers, suggesting a more compensatory mechanism of the GG mutation-a risk factor in AD pathogenesis. The positive correlation between TREM2 levels and 8-oxo-dG concentration in the caudate from DLB cases $\left(r_{\mathrm{s}}=0.881, p=0.004\right.$, Figure S1) made us curious about whether TREM2 can recognize changes in the environment or send a signal to keep microglia ready to go. Besides, a negative correlation between the concentration of TREM2 and tau fibrils was identified in the putamen of DLB cases, and CSF soluble TREM2 has been clarified as highly associated with total tau and NFT densities (phosphorylated tau) [69]. The possible mechanism of TREM2 associated tau pathology is disturbing the contact between microglia and neurons and affecting the pathological spread of tau [70].

Yield from dopamine metabolism, free radicals might induce microglia activation as indirectly indicated by the positive correlation between dopamine concentrations and TSPO densities in the putamen of PD patients $\left(r_{\mathrm{s}}=0.898, p=0.001\right.$, Figure S2). Additionally, the activated microglia, in turn, might cause dopaminergic neuronal death and damage to microglia and consequently release additional free radicals [71,72]. This hypothesis was supported by the negative correlation between MPO concentrations and TSPO densities in the putamen of PD patients carrying the heterozygous BIN1 (rs7561528) AG mutation $\left(r_{\mathrm{s}}=-0.900, p=0.037\right)$.

\subsection{Microglia Implicated in Tauopathy in the Caudate and Putamen from Patients with Neurodegenerative Diseases and Age-Matched Controls}

Increased microglial activation has been described in postmortem brain samples of AD [73,74]. The activated microglia aggregate with dopaminergic neurons in postmortem PD patient brains, suggesting microglia was involved in the pathological progress of dopaminergic neurons [75]. Our previous data shows a significant decrease in TSPO densities of the substantia nigra in AD and DLB brains compared to that of controls. It is explained by the possible microglia dystrophy in advanced neurodegeneration [13]. However, this is not unique; we discovered similar alterations in different cohorts-significant reductions of TSPO density in the striatum (caudate and putamen) of LBDs and a slight increase in TSPO density in the striatum of AD cases. Once over-activated microglia reaches an exhausting phase, it has been traditionally believed that they cannot escape their broad defects in energy metabolism, leading to a diminished immune response, namely dystrophic or senescent microglia [76,77].

Microglial burden correlates with tau burden in the main pathologically afflicted areas [78,79]. This hypothesis is further supported by a positive correlation between TSPO density and tau density in the putamen of AD patients carrying the homozygous TSPO GG mutation $\left(r_{\mathrm{s}}=0.667, p=0.050\right)$. Parallel changes in TSPO density and tau fibrils in the caudate and putamen of disease groups suggest that microglia may be associated with tau pathology. In comparison with the controls, we observed significant decreases and increases of tau fibrils in both the caudate and putamen of both LBDs and AD. Expression of tauopathy in the brains of PD and PDD might present very restricted patterns of distribution. It may be limited to dopaminergic neurons of the nigrostriatal region, a stark contrast to $\mathrm{AD}$, where tauopathy is more universally found in various brain areas $[6,80]$. Microglia may be essential for tau propagation via the release of exosomes [7]. Thus, changing microglial phenotypes might contribute to tau pathology and propagation, partially resulting in altered tau proteostasis.

The omission of other dystrophic/senescent microglia biomarkers, microglial mutation genes, a limited sample size, and significant dispersions in data are limitations to this study. We were currently inspired to continue single-nuclei RNA sequence research to remedy these limitations and address other questions that arise in this context. 


\section{Materials and Methods}

\subsection{Ethics Statement}

According to local ethical committee procedures, patients provided written consent before cognitive impairment or the next of kin provided consent antemortem or postmortem (Washington University Institutional Review Board, Washington University School of Medicine, St Louis, MO, USA). The use of tissue for autoradiography and biochemistry research was approved by the Charles F. and Joanne Knight Alzheimer's Disease Research Center and Movement Disorders Center Leadership Committees (Ethics approval reference number: T1705).

\subsection{Radioligands}

[ $\left.{ }^{3} \mathrm{H}\right]$ PBR28 (80 Ci/mmol, CAS Number: 253307-72-1) was purchased from American Radio Label (St Louis, MO, USA) and [ $\left.{ }^{3} \mathrm{H}\right] \mathrm{MK} 6240$ (21.5 Ci/mmol, CAS Number: 1841078-87-2) was purchased from Vitrax (Placentia, CA, USA).

\subsection{Subjects}

Clinically and neuropathologically well-clarified human brain tissues were obtained from the Knight ADRC and the MDC Brain Bank at Washington University School of Medicine. The tissues collected were as follows: 10 PD (7 males, 3 females) aged 69-87 (mean: $78 \pm 2$ ) years at death, 8 PDD (7 males, 1 female) aged 66-87 (mean: $77 \pm 3$ ) years at death, 10 DLB (5 males, 5 females) aged 69-89 (mean: $81 \pm 2$ ) years at death, 27 AD (13 males, 14 females) aged 62-94 (mean: $82 \pm 2)$ years at death, and 10 age-matched healthy control cases (6 males, 4 females) aged 72-93 (mean: $83 \pm 2$ ) years at death. The arbitrary clinical division between DLB and PDD was made using the criteria of McKeith et al. [81,82]. Dementia level was evaluated by Clinical Dementia Rating (CDR) [83]. Based on the CDR criteria for diagnosing dementia in PD, participants with a CDR $\geq 1$ were taken. AD pathological changes were estimated using Braak staging [84]. Braak stages of amyloid-beta deposition use letters: (A) the initial deposits in the basal neocortex, (B) deposits that extend into the adjacent areas of the neocortex, and $(\mathrm{C})$ heavy deposition throughout the entire cortex. Stages of neurofibrillary pathology represent transentorhinal (I-II), limbic (III-IV), and neocortical (V and VI). The average age and postmortem interval time did not significantly differ across groups. All the AD cases show neurofibrillary tangles (NFTs) (V: 13 cases; VI: 14 cases) and are significantly different from those of the age-matched control cases (Average amyloid-beta: A; NFTs: II). Additionally, all LBDs showed NFTs. The clinical information and pathological features are summarized in Table 1.

\subsection{Tissue Collection}

Brains were harvested at the time of autopsy, and the right hemisphere was coronally sectioned and snap-frozen using Teflon-coated aluminum plates cooled in liquid nitrogen vapor. Then, tissue blocks were placed in airtight zip-lock plastic bags and preserved at $-80^{\circ} \mathrm{C}$ until used. Frozen coronal sections $(20 \mu \mathrm{m})$ were cut using a Cryostat Microm and mounted immediately on Superfrost Plus glass slides (Fisher Scientific, Pittsburgh, 1255015, PA, USA) for autoradiography study. Striatal sub-areas, the caudate and putamen, were carefully dissected using a scalp from adjacent cryosections and tested for the biochemistry and genetic assays separately.

\subsection{Quantitative Analysis of Myeloperoxidase (MPO)}

The levels of MPO in the caudate and putamen of the study brains were measured using a Myeloperoxidase Human ELISA Kit (Abcam, ab119605, Cambridge, MA, USA) according to the protocol provided by the manufacturer. First, samples $(100 \mathrm{mg})$ were homogenized in $5 \mathrm{~mL}$ lysis buffer (Fisher Scientific, 895347, Pittsburgh, PA, USA), and the mixtures were centrifuged for $10 \mathrm{~min}$ $\left(10,000 \times g, 4{ }^{\circ} \mathrm{C}\right)$. Next, the supernatant was collected and diluted (1:10) for use with the MPO assay 
kit. Each prepared sample was detected in repeat. Known standards were added to the same assay in triplicate for accurate quantification. The detection range for MPO was 312-20,000 pg/mL, and the sensitivity was $<10 \mathrm{pg} / \mathrm{mL}$. All data were calibrated using a standard curve with a regression coefficient $r^{2}>0.99$.

\subsection{Quantitative Analysis of Poly (ADP-Ribose) (PAR)}

The concentrations of PAR in the caudate and putamen from study brains were detected with the commercially available PAR ELISA kit (Cell Biolabs, Inc., XDN-5114, San Diego, CA, USA) according to the user's manual provided by the manufacturer. First, samples $(100 \mathrm{mg})$ were homogenized in $1 \mathrm{~mL}$ RIPA buffer (Fisher Scientific, AKR-190, Pittsburgh, PA, USA) containing 1X PARP Inhibitor (1mg/mL 3-AB, Cell Biolabs, Inc., XDN-5114, San Diego, CA, USA), and the mixtures were centrifuged for $10 \mathrm{~min}$ at $10,000 \times \mathrm{g}$ at $4{ }^{\circ} \mathrm{C}$. Next, the supernatant was collected, and SDS was added to a final concentration of $1 \%$ and boiled $\left(100^{\circ} \mathrm{C}\right)$ for $5 \mathrm{~min}$. Finally, the solution was snap-cooled on the ice and centrifuged at $10,000 \times g$ for $5 \mathrm{~min}$. The resulting supernatant was used with the PAR assay kit directly. Each prepared sample was added to the assay in repeat. Known standards were added to the same assay in triplicate to perform accurate quantification. All data were calibrated from a standard curve with $r^{2}>0.98$.

\subsection{Quantitative Analysis of Triggering Receptor Expressed on Myeloid Cell 2 (TREM2)}

The expression of TREM2 in the caudate and putamen of snap-frozen brains was assessed using a TREM2 Human ELISA kit (Biomatik, EKU07882, Wilmington, DL, USA) according to the manufacturer's instructions. $100 \mathrm{mg}$ samples were homogenized in $5 \mathrm{~mL}$ lysis buffer (Fisher Scientific, 895347, Pittsburgh, PA, USA), and the mixtures were centrifuged for $10 \mathrm{~min}\left(10,000 \times g, 4{ }^{\circ} \mathrm{C}\right)$. The supernatant was collected and diluted (1:5) for use with the TREM2 assay kit. Known standards were added in triplicate, and each sample was detected in repeat in the same assay. The detection range for MPO was $62.5-4000 \mathrm{pg} / \mathrm{mL}$ and the sensitivity was $<26.2 \mathrm{pg} / \mathrm{mL}$. All data were calculated using a standard curve with $r^{2}>0.99$.

\subsection{Autoradiography}

\subsubsection{Quantification of Total Radioactivity}

Dried slides were made by covering the free side with copper foil tape. Then slides were placed into a gas chamber containing a balance of argon and triethylamine (Sigma-Aldrich, BP616-500, St. Louis, MO, USA) as part of a gaseous detector system, Beta Imager 2000Z Digital Beta Imaging System (Biospace, Nesles la Vallée, France) with a sensitivity limit of $0.07 \mathrm{dpm} / \mathrm{mm}^{2}$. When a homogenous state was achieved, further exposure for $20 \mathrm{~h}$ yielded high-quality images. A $\left[{ }^{3} \mathrm{H}\right]$ microscale with known radioactivity (ranging from 0 to $36.3 \mathrm{nCi} / \mathrm{mg}$ ) was counted with each section and used to establish a standard curve with a correlation coefficient of $r^{2}>0.99$. Quantitative analysis was accomplished with the program Beta-Vision Plus (BioSpace, Nesles la Vallée, France) for each region of interest.

\subsubsection{8-kDa Translocator Protein (TSPO) Binding}

TSPO binding sites were labeled with $\left[{ }^{3} \mathrm{H}\right] \mathrm{PBR} 28$. Brain sections were incubated at room temperature (RT) for $30 \mathrm{~min}$ in a buffer solution containing $2 \mathrm{nmol} / \mathrm{L}\left[{ }^{3} \mathrm{H}\right] \mathrm{PBR} 28$ (American Radio Label, ART2270, MO, USA) and followed by rinses ( $1 \mathrm{~min} \times 5$ times). Nonspecific binding was determined using the adjacent sections in $1 \mu \mathrm{mol} / \mathrm{L}$ PK11195 (Bio-Techne Corporation, 0670, Minneapolis, MN, USA) as previously described [13].

\subsubsection{Tau Fibrils Binding}

Tau fibrils binding sites were labeled with $\left[{ }^{3} \mathrm{H}\right] \mathrm{MK} 6240$. Brain sections were incubated at RT for $30 \mathrm{~min}$ in a buffer solution containing $2 \mathrm{nmol} / \mathrm{L}\left[{ }^{3} \mathrm{H}\right] \mathrm{MK} 6240$ (Vitrax, VT298, Placentia, CA, USA) and 
followed by rinses ( $1 \mathrm{~min} \times 5$ times). Nonspecific binding was determined using the adjacent sections in the presence of $10 \mu \mathrm{mol} / \mathrm{L}$ T807 (MedChemExpress, HY-101184, Monmouth Junction, NJ, USA).

\subsection{Genotype}

According to the manufacturer's instruction, total DNA in the striatum of study brains was extracted using the Qiagen QIAamp DNA Mini Kit (Qiagen, Valencia, 51304, CA, USA). A NanoDrop 1000 spectrophotometer (Thermo Fisher, Pittsburgh, PA, USA, RRID: SCR_016517) was utilized to measure DNA integrity and purity. Samples interrogated rs6971 (TSPO), rs75932628 (TREM2), and rs7561528 (BIN1) separately using Taqman SNP Assays (ThermoFisher Scientific, Grand Island, NY, USA). A master mix of $0.5 \mathrm{uL}$ of $40 \times$ Taqman SNP Assay, $40 \mathrm{ng}$ of DNA from each sample, and $10 \mathrm{uL}$ of Taqman Universal PCR was used to amplify the specific allele for each specimen in a total reaction volume of $20 \mathrm{uL}$. The cycling program consisted of $10 \mathrm{~min}$ at $95{ }^{\circ} \mathrm{C}$, followed by 40 cycles of $95^{\circ} \mathrm{C}$ for $15 \mathrm{sec}$ and then $60^{\circ} \mathrm{C}$ for $1 \mathrm{~min}$ on a CFX96 thermocycler (Biorad). The calls were analyzed and viewed using the Bio-Rad CFX Manager software.

\subsection{Statistical Analysis}

Data were expressed as means \pm SEM. The statistical analyses were performed using all data without any further normalization. A one-way analysis of variance (ANOVA) with Tukey's post-hoc-tests was used to estimate the overall significance of normally distributed datasets, and a Kruskal-Wallis ANOVA with Dunn's multiple comparison test was run if the dataset was not normally distributed. A student's unpaired t-test was used to assess the difference between groups. Spearman's correlation coefficient ( $\mathrm{rs}$ ) was calculated to verify the strength of the correlation between continuous variables. TSPO (rs6971) and BIN1 (rs7561528) genotype distributions (AA vs. AG vs. GG) were compared between disease and control groups with a Chi-square test. Statistical analyses were carried out using GraphPad Prism 6.0 (RRID: SCR_002798) for Windows and IBM SPSS Statistics version 23 (RRID: SCR_002865). In all cases, $p<0.05$ was considered statistically significant. No randomization, blinding, or sample size calculations were performed during experimentation or statistical analyses. Error bars on the scatter dot plots represent standard error of the mean.

\section{Conclusions}

This study discusses how ROS interacts with microglia in the striatum of patients with advanced neurodegenerative diseases based on the region-specific alteration in levels of microglial neurobiological phenotypes: MPO, PAR, and TREM2. The parallel changes of TSPO densities and tau fibrils provide a better understanding of how microglia are implicated in tauopathy. This study is the first to establish genotype-phenotype relationships to some extent, address how some SNPs relate to specific aspects of microglial function and lead to tau proteostasis disturbance. Nevertheless, even if some gray areas persist regarding the mechanisms and interactions between microglia and tauopathy, future directions for study are already emerging with this framework.

Supplementary Materials: The following are available online at http://www.mdpi.com/1422-0067/21/17/6047/s1, Figure S1. Correlation between TREM2 levels and 8-oxo-dG concentration in the caudate from DLB cases. $r_{\mathrm{S}}$, the Spearman's rank correlation coefficient. Figure S2. Correlation between dopamine concentrations and TSPO densities in the putamen of PD patients. $r_{\mathrm{s}}$, the Spearman's rank correlation coefficient. Figure S3. Correlation between TREM2 levels in the putamen from PDD cases and Disease Progression. $r_{\mathrm{s}}$, the Spearman's rank correlation coefficient. Figure S4. Correlation between TREM2 levels in the putamen from LBDs and PD stage. $r_{\mathrm{S}}$, the Spearman's rank correlation coefficient.

Author Contributions: Study concept, design, and supervision: J.X. Qualitative analysis of data: H.L., W.C.K., P.Y. and J.X. Statistical analysis and interpretation: H.L. and J.X. Preparation of tissue: W.C.K., H.L., Y.G., P.Y. and J.X. Drafting of the manuscript: H.L. and J.X. Preparation of figures/tables: H.L., W.C.K., P.Y. and J.X. Critical revision of the manuscript for important intellectual content: T.L.S.B., J.C.M., R.J.B. and J.S.P. Obtained funding: J.X. All authors have read and agreed to the published version of the manuscript. 
Funding: This work was supported by NIH R01 NS092865, R01 AG052550, P01 AG026276, P01 AG03991, and P50 AG05681.

Acknowledgments: We thank all participants and their families for their commitment and dedication to advancing research of diagnosis and treatment for P.D. and A.D., as well as the Knight-ADRC and MDC research staff for their contributions. We also thank Nigel Cairns, Erin E. Franklin, and Michael Baxter of the Knight Alzheimer Disease Research Center Neuropathology Core at Washington University School of Medicine for coordination of the tissue preparation and expert technical assistance.

Conflicts of Interest: The authors declare no conflict of interest.

\section{Abbreviations}

$\begin{array}{ll}\text { AD } & \text { Alzheimer's disease } \\ \text { PD } & \text { Parkinson's disease } \\ \text { MPO } & \text { Myeloperoxidase } \\ \text { PAR } & \text { Poly (ADP-Ribose) } \\ \text { TREM2 } & \text { Triggering receptors expressed on myeloid cell 2 } \\ \text { ELISA } & \text { Enzyme-linked immunosorbent assay } \\ \text { TSPO } & \text { Translocator protein } \\ \text { DLB } & \text { Dementia with Lewy body } \\ \text { PDD } & \text { Parkinson's disease dementia } \\ \text { LBDs } & \text { Lewy body diseases } \\ \text { BIN1 } & \text { Bridging integrator 1 } \\ \text { SNP } & \text { Single-nucleotide polymorphism } \\ \text { MAPT } & \text { Microtubule-associated protein tau } \\ \text { NFTs } & \text { Neurofibrillary tangles } \\ \text { PHFs } & \text { Paired helical filaments } \\ \text { CNS } & \text { Central nervous system } \\ \text { MPTP } & \text { 1-Methyl-4-phenyl-1, 2,3,6-tetrahydropyridine } \\ \text { ERK } & \text { Extracellular signal-regulated kinase } \\ \text { SNc } & \text { Substantia nigra pars compacta } \\ \text { ROS } & \text { Reactive oxygen species } \\ \text { PARP } & \text { Poly (ADP-ribose) polymerase } \\ \text { FTD } & \text { Frontotemporal dementia } \\ \text { RT } & \text { Room temperature } \\ \text { ANOVA } & \text { Analysis of variance } \\ \text { MSA } & \text { Multiple system atrophy } \\ \text { ALS } & \text { Amyotrophic lateral sclerosis } \\ \text { APOE } & \text { Cerebrospinal fluid } \\ \text { NAD } & \\ \text { CSF } & \end{array}$

\section{References}

1. Nelson, P.T.; Alafuzoff, I.; Bigio, E.H.; Bouras, C.; Braak, H.; Cairns, N.J.; Castellani, R.J.; Crain, B.J.; Davies, P.; Del Tredici, K.; et al. Correlation of Alzheimer disease neuropathologic changes with cognitive status: A review of the literature. J. Neuropathol. Exp. Neurol. 2012, 71, 362-381. [CrossRef] [PubMed]

2. Shaw-Smith, C.; Pittman, A.M.; Willatt, L.; Martin, H.; Rickman, L.; Gribble, S.; Curley, R.; Cumming, S.; Dunn, C.; Kalaitzopoulos, D.; et al. Microdeletion encompassing MAPT at chromosome 17q21.3 is associated with developmental delay and learning disability. Nat. Genet. 2006, 38, 1032-1037. [CrossRef] [PubMed]

3. Selden, N.; Mesulam, M.M.; Geula, C. Human striatum: The distribution of neurofibrillary tangles in Alzheimer's disease. Brain Res. 1994, 648, 327-331. [CrossRef]

4. Iseki, E.; Matsushita, M.; Kosaka, K.; Suzuki, K.; Amano, N.; Saito, A. Morphological characteristics of senile plaques in familial Alzheimer's disease. Acta Neuropathol. 1990, 80, 227-232. [CrossRef] [PubMed] 
5. Kotzbauer, P.T.; Cairns, N.J.; Campbell, M.C.; Willis, A.W.; Racette, B.A.; Tabbal, S.D.; Perlmutter, J.S. Pathologic accumulation of alpha-synuclein and Abeta in Parkinson disease patients with dementia. Arch. Neurol. 2012, 69, 1326-1331. [CrossRef]

6. Kaul, T.; Credle, J.; Haggerty, T.; Oaks, A.W.; Masliah, E.; Sidhu, A. Region-specific tauopathy and synucleinopathy in brain of the alpha-synuclein overexpressing mouse model of Parkinson's disease. BMC Neurosci. 2011, 12, 79. [CrossRef]

7. Asai, H.; Ikezu, S.; Tsunoda, S.; Medalla, M.; Luebke, J.; Haydar, T.; Wolozin, B.; Butovsky, O.; Kügler, S.; Ikezu, T. Depletion of microglia and inhibition of exosome synthesis halt tau propagation. Nat. Neurosci. 2015, 18, 1584-1593. [CrossRef]

8. Vogels, T.; Murgoci, A.N.; Hromádka, T. Intersection of pathological tau and microglia at the synapse. Acta Neuropathol. Commun. 2019, 7, 109. [CrossRef]

9. Politis, M.; Su, P.; Piccini, P. Imaging of microglia in patients with neurodegenerative disorders. Front. Pharm. 2012, 3, 96. [CrossRef]

10. Yanguas-Casas, N.; Crespo-Castrillo, A.; de Ceballos, M.L.; Chowen, J.A.; Azcoitia, I.; Arevalo, M.A.; Garcia-Segura, L.M. Sex differences in the phagocytic and migratory activity of microglia and their impairment by palmitic acid. Glia 2018, 66, 522-537. [CrossRef]

11. Sarkar, S.; Lu, E.; Raymick, J.; Hanig, J.; Gu, Q. ERK/MAP Kinase Activation is Evident in Activated Microglia of the Striatum and Substantia Nigra in an Acute and Chronically-Induced Mouse Model of Parkinson's Disease. Curr. Neurovasc. Res. 2018, 15, 336-344. [CrossRef] [PubMed]

12. Hossain, M.M.; Weig, B.; Reuhl, K.; Gearing, M.; Wu, L.-J.; Richardson, J.R. The anti-parkinsonian drug zonisamide reduces neuroinflammation: Role of microglial $\mathrm{Na}(\mathrm{v})$ 1.6. Exp. Neurol. 2018, 308, 111-119. [CrossRef] [PubMed]

13. Xu, J.; Sun, J.; Perrin, R.J.; Mach, R.H.; Bales, K.R.; Morris, J.C.; Benzinger, T.L.S.; Holtzman, D.M. Translocator protein in late stage Alzheimer's disease and Dementia with Lewy bodies brains. Ann. Clin. Transl. Neurol. 2019, 6, 1423-1434. [CrossRef] [PubMed]

14. Ghadery, C.; Koshimori, Y.; Coakeley, S.; Harris, M.; Rusjan, P.; Kim, J.; Houle, S.; Strafella, A.P. Microglial activation in Parkinson's disease using [(18)F]-FEPPA. J. Neuroinflamm. 2017, 14, 8. [CrossRef]

15. Han, F.; Perrin, R.J.; Wang, Q.; Wang, Y.; Perlmutter, J.S.; Morris, J.C.; Benzinger, T.L.S.; Xu, J. Neuroinflammation and Myelin Status in Alzheimer's Disease, Parkinson's Disease, and Normal Aging Brains: A Small Sample Study. Parkinson's Dis. 2019, 2019, 7975407. [CrossRef]

16. Hanisch, U.-K.; Kettenmann, H. Microglia: Active sensor and versatile effector cells in the normal and pathologic brain. Nat. Neurosci. 2007, 10, 1387-1394. [CrossRef]

17. Agrawal, R.; Sharma, P.K.; Rao, G.S. Release of iron from ferritin by metabolites of benzene and superoxide radical generating agents. Toxicology 2001, 168, 223-230. [CrossRef]

18. Biemond, P.; van Eijk, H.G.; Swaak, A.J.; Koster, J.F. Iron mobilization from ferritin by superoxide derived from stimulated polymorphonuclear leukocytes. Possible mechanism in inflammation diseases. J. Clin. Investig. 1984, 73, 1576-1579. [CrossRef]

19. Li, H.; Yang, P.; Knight, W.; Guo, Y.; Perlmutter, J.S.; Benzinger, T.L.S.; Morris, J.C.; Xu, J. The interactions of dopamine and oxidative damage in the striatum of patients with neurodegenerative diseases. J. Neurochem. 2020, 152, 235-251. [CrossRef]

20. Mander, P.K.; Jekabsone, A.; Brown, G.C. Microglia proliferation is regulated by hydrogen peroxide from NADPH oxidase. J. Immunol. 2006, 176, 1046-1052. [CrossRef]

21. Reynolds, W.F.; Rhees, J.; Maciejewski, D.; Paladino, T.; Sieburg, H.; Maki, R.A.; Masliah, E. Myeloperoxidase polymorphism is associated with gender specific risk for Alzheimer's disease. Exp. Neurol. 1999, 155, 31-41. [CrossRef] [PubMed]

22. Green, P.S.; Mendez, A.J.; Jacob, J.S.; Crowley, J.R.; Growdon, W.; Hyman, B.T.; Heinecke, J.W. Neuronal expression of myeloperoxidase is increased in Alzheimer's disease. J. Neurochem. 2004, 90, 724-733. [CrossRef] [PubMed]

23. Sugiyama, S.; Kugiyama, K.; Aikawa, M.; Nakamura, S.; Ogawa, H.; Libby, P. Hypochlorous acid, a macrophage product, induces endothelial apoptosis and tissue factor expression: Involvement of myeloperoxidase-mediated oxidant in plaque erosion and thrombogenesis. Arterioscler. Thromb. Vasc. Biol. 2004, 24, 1309-1314. [CrossRef] [PubMed] 
24. Martínez-Zamudio, R.I.; Ha, H.C. PARP1 enhances inflammatory cytokine expression by alteration of promoter chromatin structure in microglia. Brain Behav. 2014, 4, 552-565. [CrossRef]

25. Zhang, Y.; Feng, S.; Nie, K.; Li, Y.; Gao, Y.; Gan, R.; Wang, L.; Li, B.; Sun, X.; Wang, L.; et al. TREM2 modulates microglia phenotypes in the neuroinflammation of Parkinson's disease. Biochem. Biophys. Res. Commun. 2018, 499, 797-802. [CrossRef]

26. Kleinberger, G.; Brendel, M.; Mracsko, E.; Wefers, B.; Groeneweg, L.; Xiang, X.; Focke, C.; Deußing, M.; Suárez-Calvet, M.; Mazaheri, F.; et al. The FTD-like syndrome causing TREM2 T66M mutation impairs microglia function, brain perfusion, and glucose metabolism. EMBO J. 2017, 36, 1837-1853. [CrossRef]

27. Finelli, D.; Rollinson, S.; Harris, J.; Jones, M.; Richardson, A.; Gerhard, A.; Snowden, J.; Mann, D.; Pickering-Brown, S. TREM2 analysis and increased risk of Alzheimer's disease. Neurobiol. Aging 2015, 36, 546.e9-546.e13. [CrossRef]

28. Rayaprolu, S.; Mullen, B.; Baker, M.; Lynch, T.; Finger, E.; Seeley, W.W.; Hatanpaa, K.J.; Lomen-Hoerth, C.; Kertesz, A.; Bigio, E.H.; et al. TREM2 in neurodegeneration: Evidence for association of the p.R47H variant with frontotemporal dementia and Parkinson's disease. Mol. Neurodegener. 2013, 8, 19. [CrossRef]

29. Crotti, A.; Sait, H.R.; McAvoy, K.M.; Estrada, K.; Ergun, A.; Szak, S.; Marsh, G.; Jandreski, L.; Peterson, M.; Reynolds, T.L.; et al. BIN1 favors the spreading of Tau via extracellular vesicles. Sci. Rep. 2019, 9, 9477. [CrossRef]

30. Hu, X.; Pickering, E.; Liu, Y.C.; Hall, S.; Fournier, H.; Katz, E.; Dechairo, B.; John, S.; Van Eerdewegh, P.; Soares, H. Meta-analysis for genome-wide association study identifies multiple variants at the BIN1 locus associated with late-onset Alzheimer's disease. PLoS ONE 2011, 6, e16616. [CrossRef]

31. Xiao, Q.; Liu, Z.J.; Tao, S.; Sun, Y.M.; Jiang, D.; Li, H.L.; Chen, H.; Liu, X.; Lapin, B.; Wang, C.H.; et al. Risk prediction for sporadic Alzheimer's disease using genetic risk score in the Han Chinese population. Oncotarget 2015, 6, 36955-36964. [CrossRef] [PubMed]

32. Zhou, F.; Haina, D. The bridging integrator 1 Gene rs7561528 polymorphism contributes to Alzheimer's disease susceptibility in East Asian and Caucasian populations. Clin. Chim. Acta 2017, 469, 13-21. [CrossRef] [PubMed]

33. Wang, Y.Q.; Tang, B.S.; Yang, Y.; Cui, Y.T.; Kang, J.F.; Liu, Z.H.; Li, K.; Sun, Q.Y.; Xu, Q.; Yan, X.X.; et al. Relationship between Alzheimer's disease GWAS-linked top hits and risk of Parkinson's disease with or without cognitive decline: A Chinese population-based study. Neurobiol. Aging 2016, 39, 217.e9-217.e11. [CrossRef] [PubMed]

34. Dai, D.L.; Tropea, T.F.; Robinson, J.L.; Suh, E.; Hurtig, H.; Weintraub, D.; Van Deerlin, V.; Lee, E.B.; Trojanowski, J.Q.; Chen-Plotkin, A.S. ADNC-RS, a clinical-genetic risk score, predicts Alzheimer's pathology in autopsy-confirmed Parkinson's disease and Dementia with Lewy bodies. Acta Neuropathol. 2020. [CrossRef] [PubMed]

35. Jonsson, T.; Stefansson, H.; Steinberg, S.; Jonsdottir, I.; Jonsson, P.V.; Snaedal, J.; Bjornsson, S.; Huttenlocher, J.; Levey, A.I.; Lah, J.J.; et al. Variant of TREM2 associated with the risk of Alzheimer's disease. N. Engl. J. Med. 2013, 368, 107-116. [CrossRef] [PubMed]

36. Ryabokon, N.I.; Goncharova, R.I.; Duburs, G.; Hancock, R.; Rzeszowska-Wolny, J. Changes in poly(ADP-ribose) level modulate the kinetics of DNA strand break rejoining. Mutat. Res. 2008, 637, 173-181. [CrossRef]

37. Mehrabadi, A.R.; Korolainen, M.A.; Odero, G.; Miller, D.W.; Kauppinen, T.M. Poly(ADP-ribose) polymerase-1 regulates microglia mediated decrease of endothelial tight junction integrity. Neurochem. Int. 2017, 108, 266-271. [CrossRef]

38. Frank, S.; Burbach, G.J.; Bonin, M.; Walter, M.; Streit, W.; Bechmann, I.; Deller, T. TREM2 is upregulated in amyloid plaque-associated microglia in aged APP23 transgenic mice. Glia 2008, 56, 1438-1447. [CrossRef]

39. Takahashi, K.; Rochford, C.D.; Neumann, H. Clearance of apoptotic neurons without inflammation by microglial triggering receptor expressed on myeloid cells-2. J. Exp. Med. 2005, 201, 647-657. [CrossRef]

40. Sun, M.; Zhu, M.; Chen, K.; Nie, X.; Deng, Q.; Hazlett, L.D.; Wu, Y.; Li, M.; Wu, M.; Huang, X. TREM-2 promotes host resistance against Pseudomonas aeruginosa infection by suppressing corneal inflammation via a PI3K/Akt signaling pathway. Investig. Ophthalmol. Vis. Sci. 2013, 54, 3451-3462. [CrossRef]

41. Masuda, T.; Sankowski, R.; Staszewski, O.; Prinz, M. Microglia Heterogeneity in the Single-Cell Era. Cell Rep. 2020, 30, 1271-1281. [CrossRef] [PubMed] 
42. Cente, M.; Filipcik, P.; Mandakova, S.; Zilka, N.; Krajciova, G.; Novak, M. Expression of a truncated human tau protein induces aqueous-phase free radicals in a rat model of tauopathy: Implications for targeted antioxidative therapy. J. Alzheimer's Dis. 2009, 17, 913-920. [CrossRef] [PubMed]

43. Chen, Y.; Chen, X.; Guo, X.; Song, W.; Cao, B.; Wei, Q.; Ou, R.; Zhao, B.; Shang, H.F. Assessment of TREM2 rs75932628 association with Parkinson's disease and multiple system atrophy in a Chinese population. Neurol. Sci. 2015, 36, 1903-1906. [CrossRef] [PubMed]

44. Chen, X.; Chen, Y.; Wei, Q.; Guo, X.; Cao, B.; Ou, R.; Zhao, B.; Shang, H.F. Assessment of TREM2 rs75932628 association with amyotrophic lateral sclerosis in a Chinese population. J. Neurol. Sci. 2015, 355, 193-195. [CrossRef] [PubMed]

45. Ramensky, V.; Bork, P.; Sunyaev, S. Human non-synonymous SNPs: Server and survey. Nucleic Acids Res. 2002, 30, 3894-3900. [CrossRef]

46. Costa, B.; Pini, S.; Gabelloni, P.; Da Pozzo, E.; Abelli, M.; Lari, L.; Preve, M.; Lucacchini, A.; Cassano, G.B.; Martini, C. The spontaneous Ala147Thr amino acid substitution within the translocator protein influences pregnenolone production in lymphomonocytes of healthy individuals. Endocrinology 2009, 150, 5438-5445. [CrossRef]

47. Costa, B.; Pini, S.; Martini, C.; Abelli, M.; Gabelloni, P.; Landi, S.; Muti, M.; Gesi, C.; Lari, L.; Cardini, A.; et al. Ala147Thr substitution in translocator protein is associated with adult separation anxiety in patients with depression. Psychiatr. Genet. 2009, 19, 110-111. [CrossRef]

48. Gui, Y.; Marks, J.D.; Das, S.; Hyman, B.T.; Serrano-Pozo, A. Characterization of the 18 kDa translocator protein (TSPO) expression in post-mortem normal and Alzheimer's disease brains. Brain Pathol. 2020, 30, 151-164. [CrossRef]

49. Owen, D.R.; Yeo, A.J.; Gunn, R.N.; Song, K.; Wadsworth, G.; Lewis, A.; Rhodes, C.; Pulford, D.J.; Bennacef, I.; Parker, C.A.; et al. An 18-kDa translocator protein (TSPO) polymorphism explains differences in binding affinity of the PET radioligand PBR28. J. Cereb. Blood Flow Metab. 2012, 32, 1-5. [CrossRef]

50. Owen, D.R.; Gunn, R.N.; Rabiner, E.A.; Bennacef, I.; Fujita, M.; Kreisl, W.C.; Innis, R.B.; Pike, V.W.; Reynolds, R.; Matthews, P.M.; et al. Mixed-affinity binding in humans with 18-kDa translocator protein ligands. J. Nucl. Med. 2011, 52, 24-32. [CrossRef]

51. Scarf, A.M.; Kassiou, M. The translocator protein. J. Nucl. Med. 2011, 52, 677-680. [CrossRef] [PubMed]

52. Prossin, A.R.; Chandler, M.; Ryan, K.A.; Saunders, E.F.; Kamali, M.; Papadopoulos, V.; Zöllner, S.; Dantzer, R.; McInnis, M.G. Functional TSPO polymorphism predicts variance in the diurnal cortisol rhythm in bipolar disorder. Psychoneuroendocrinology 2018, 89, 194-202. [CrossRef] [PubMed]

53. Kunkle, B.W.; Grenier-Boley, B.; Sims, R.; Bis, J.C.; Damotte, V.; Naj, A.C.; Boland, A.; Vronskaya, M.; van der Lee, S.J.; Amlie-Wolf, A.; et al. Genetic meta-analysis of diagnosed Alzheimer's disease identifies new risk loci and implicates $A \beta$, tau, immunity and lipid processing. Nat. Genet. 2019, 51, 414-430. [CrossRef] [PubMed]

54. Klebanoff, S.J.; Kettle, A.J.; Rosen, H.; Winterbourn, C.C.; Nauseef, W.M. Myeloperoxidase: A front-line defender against phagocytosed microorganisms. J. Leukoc. Biol. 2013, 93, 185-198. [CrossRef] [PubMed]

55. Casciaro, M.; Di Salvo, E.; Pace, E.; Ventura-Spagnolo, E.; Navarra, M.; Gangemi, S. Chlorinative stress in age-related diseases: A literature review. Immun. Ageing 2017, 14, 21. [CrossRef]

56. Winterbourn, C.C.; Kettle, A.J. Biomarkers of myeloperoxidase-derived hypochlorous acid. Free Radic. Biol. Med. 2000, 29, 403-409. [CrossRef]

57. Lefkowitz, D.L.; Lefkowitz, S.S. Microglia and myeloperoxidase: A deadly partnership in neurodegenerative disease. Free Radic. Biol. Med. 2008, 45, 726-731. [CrossRef]

58. Gellhaar, S.; Sunnemark, D.; Eriksson, H.; Olson, L.; Galter, D. Myeloperoxidase-immunoreactive cells are significantly increased in brain areas affected by neurodegeneration in Parkinson's and Alzheimer's disease. Cell Tissue Res. 2017, 369, 445-454. [CrossRef]

59. Choi, D.K.; Pennathur, S.; Perier, C.; Tieu, K.; Teismann, P.; Wu, D.C.; Jackson-Lewis, V.; Vila, M.; Vonsattel, J.P.; Heinecke, J.W.; et al. Ablation of the inflammatory enzyme myeloperoxidase mitigates features of Parkinson's disease in mice. J. Neurosci. 2005, 25, 6594-6600. [CrossRef]

60. Chen, I.C.; Lin, T.H.; Hsieh, Y.H.; Chao, C.Y.; Wu, Y.R.; Chang, K.H.; Lee, M.C.; Lee-Chen, G.J.; Chen, C.M. Formulated Chinese Medicine Shaoyao Gancao Tang Reduces Tau Aggregation and Exerts Neuroprotection through Anti-Oxidation and Anti-Inflammation. Oxid. Med. Cell. Longev. 2018, 2018, 9595741. [CrossRef] 
61. Malanga, M.; Althaus, F.R. The role of poly(ADP-ribose) in the DNA damage signaling network. Biochem. Cell Biol. 2005, 83, 354-364. [CrossRef] [PubMed]

62. D'Amours, D.; Desnoyers, S.; D'Silva, I.; Poirier, G.G. Poly(ADP-ribosyl)ation reactions in the regulation of nuclear functions. Biochem. J. 1999, 342 Pt 2, 249-268. [CrossRef]

63. Langelier, M.F.; Eisemann, T.; Riccio, A.A.; Pascal, J.M. PARP family enzymes: Regulation and catalysis of the poly(ADP-ribose) posttranslational modification. Curr. Opin. Struct. Biol. 2018, 53, 187-198. [CrossRef]

64. Kam, T.I.; Mao, X.; Park, H.; Chou, S.C.; Karuppagounder, S.S.; Umanah, G.E.; Yun, S.P.; Brahmachari, S.; Panicker, N.; Chen, R.; et al. Poly(ADP-ribose) drives pathologic $\alpha$-synuclein neurodegeneration in Parkinson's disease. Science 2018, 362, eaat8407. [CrossRef] [PubMed]

65. Patterson, L.; Rushton, S.P.; Attems, J.; Thomas, A.J.; Morris, C.M. Degeneration of dopaminergic circuitry influences depressive symptoms in Lewy body disorders. Brain Pathol. 2019, 29, 544-557. [CrossRef] [PubMed]

66. Correani, V.; Martire, S.; Mignogna, G.; Caruso, L.B.; Tempera, I.; Giorgi, A.; Grieco, M.; Mosca, L.; Schinina, M.E.; Maras, B.; et al. Poly(ADP-ribosylated) proteins in beta-amyloid peptide-stimulated microglial cells. Biochem. Pharm. 2019, 167, 50-57. [CrossRef] [PubMed]

67. Belloli, S.; Pannese, M.; Buonsanti, C.; Maiorino, C.; Di Grigoli, G.; Carpinelli, A.; Monterisi, C.; Moresco, R.M.; Panina-Bordignon, P. Early upregulation of $18-\mathrm{kDa}$ translocator protein in response to acute neurodegenerative damage in TREM2-deficient mice. Neurobiol. Aging 2017, 53, 159-168. [CrossRef]

68. Mori, Y.; Yoshino, Y.; Ochi, S.; Yamazaki, K.; Kawabe, K.; Abe, M.; Kitano, T.; Ozaki, Y.; Yoshida, T.; Numata, S.; et al. TREM2 mRNA Expression in Leukocytes Is Increased in Alzheimer's Disease and Schizophrenia. PLoS ONE 2015, 10, e0136835. [CrossRef]

69. Ewers, M.; Franzmeier, N.; Suárez-Calvet, M.; Morenas-Rodriguez, E.; Caballero, M.A.A.; Kleinberger, G.; Piccio, L.; Cruchaga, C.; Deming, Y.; Dichgans, M.; et al. Increased soluble TREM2 in cerebrospinal fluid is associated with reduced cognitive and clinical decline in Alzheimer's disease. Sci. Transl. Med. 2019, 11, eaav6221. [CrossRef]

70. Singh, A.K.; Mishra, G.; Maurya, A.; Awasthi, R.; Kumari, K.; Thakur, A.; Rai, A.; Rai, G.K.; Sharma, B.; Kulkarni, G.T.; et al. Role of TREM2 in Alzheimer's Disease and its Consequences on $\beta$ - Amyloid, Tau and Neurofibrillary Tangles. Curr. Alzheimer Res. 2019, 16, 1216-1229. [CrossRef]

71. Członkowska, A.; Kurkowska-Jastrzebska, I.; Członkowski, A.; Peter, D.; Stefano, G.B. Immune processes in the pathogenesis of Parkinson's disease-A potential role for microglia and nitric oxide. Med. Sci. Monit. Int. Med. J. Exp. Clin. Res. 2002, 8, Ra165-Ra177.

72. Verina, T.; Kiihl, S.F.; Schneider, J.S.; Guilarte, T.R. Manganese exposure induces microglia activation and dystrophy in the substantia nigra of non-human primates. Neurotoxicology 2011, 32, 215-226. [CrossRef] [PubMed]

73. Heneka, M.T.; Carson, M.J.; El Khoury, J.; Landreth, G.E.; Brosseron, F.; Feinstein, D.L.; Jacobs, A.H.; Wyss-Coray, T.; Vitorica, J.; Ransohoff, R.M.; et al. Neuroinflammation in Alzheimer's disease. Lancet Neurol. 2015, 14, 388-405. [CrossRef]

74. Prokop, S.; Miller, K.R.; Heppner, F.L. Microglia actions in Alzheimer's disease. Acta Neuropathol. 2013, 126, 461-477. [CrossRef] [PubMed]

75. Imamura, K.; Hishikawa, N.; Sawada, M.; Nagatsu, T.; Yoshida, M.; Hashizume, Y. Distribution of major histocompatibility complex class II-positive microglia and cytokine profile of Parkinson's disease brains. Acta Neuropathol. 2003, 106, 518-526. [CrossRef]

76. Baik, S.H.; Kang, S.; Lee, W.; Choi, H.; Chung, S.; Kim, J.I.; Mook-Jung, I. A Breakdown in Metabolic Reprogramming Causes Microglia Dysfunction in Alzheimer's Disease. Cell Metab. 2019, 30, 493-507.e6. [CrossRef]

77. Streit, W.J.; Braak, H.; Xue, Q.S.; Bechmann, I. Dystrophic (senescent) rather than activated microglial cells are associated with tau pathology and likely precede neurodegeneration in Alzheimer's disease. Acta Neuropathol. 2009, 118, 475-485. [CrossRef]

78. DiPatre, P.L.; Gelman, B.B. Microglial cell activation in aging and Alzheimer disease: Partial linkage with neurofibrillary tangle burden in the hippocampus. J. Neuropathol. Exp. Neurol. 1997, 56, 143-149. [CrossRef]

79. Ishizawa, K.; Dickson, D.W. Microglial activation parallels system degeneration in progressive supranuclear palsy and corticobasal degeneration. J. Neuropathol. Exp. Neurol. 2001, 60, 647-657. [CrossRef] 
80. Wills, J.; Jones, J.; Haggerty, T.; Duka, V.; Joyce, J.N.; Sidhu, A. Elevated tauopathy and alpha-synuclein pathology in postmortem Parkinson's disease brains with and without dementia. Exp. Neurol. 2010, 225, 210-218. [CrossRef]

81. McKeith, I.G.; Dickson, D.W.; Lowe, J.; Emre, M.; O’Brien, J.T.; Feldman, H.; Cummings, J.; Duda, J.E.; Lippa, C.; Perry, E.K.; et al. Diagnosis and management of dementia with Lewy bodies: Third report of the DLB Consortium. Neurology 2005, 65, 1863-1872. [CrossRef] [PubMed]

82. Hughes, A.J.; Daniel, S.E.; Kilford, L.; Lees, A.J. Accuracy of clinical diagnosis of idiopathic Parkinson's disease: A clinico-pathological study of 100 cases. J. Neurol. Neurosurg. Psychiatr. 1992, 55, 181-184. [CrossRef] [PubMed]

83. Emre, M.; Aarsland, D.; Brown, R.; Burn, D.J.; Duyckaerts, C.; Mizuno, Y.; Broe, G.A.; Cummings, J.; Dickson, D.W.; Gauthier, S.; et al. Clinical diagnostic criteria for dementia associated with Parkinson's disease. Mov. Disord. Off. J. Mov. Disord. Soc. 2007, 22, 1689-1707, quiz 1837. [CrossRef] [PubMed]

84. Thal, D.R.; Braak, H. Post-mortem diagnosis of Alzheimer's disease. Der. Pathol. 2005, 26, 201-213. [CrossRef]

(C) 2020 by the authors. Licensee MDPI, Basel, Switzerland. This article is an open access article distributed under the terms and conditions of the Creative Commons Attribution (CC BY) license (http://creativecommons.org/licenses/by/4.0/). 